\title{
Decision Support Capabilities for Future
} Technology Requirements

Michael P. Case, William D. Goran, Thomas A. Gunther, January 2001 Jeffery P. Holland, Douglas M. Johnston, Gene Lessard, and Wayne J. Schmidt

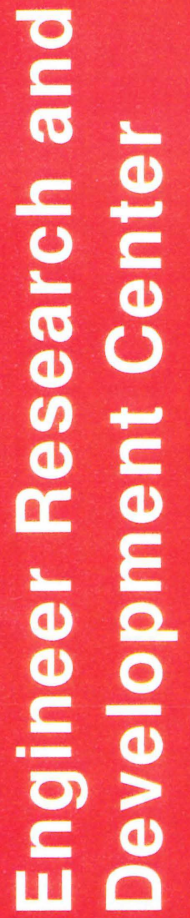




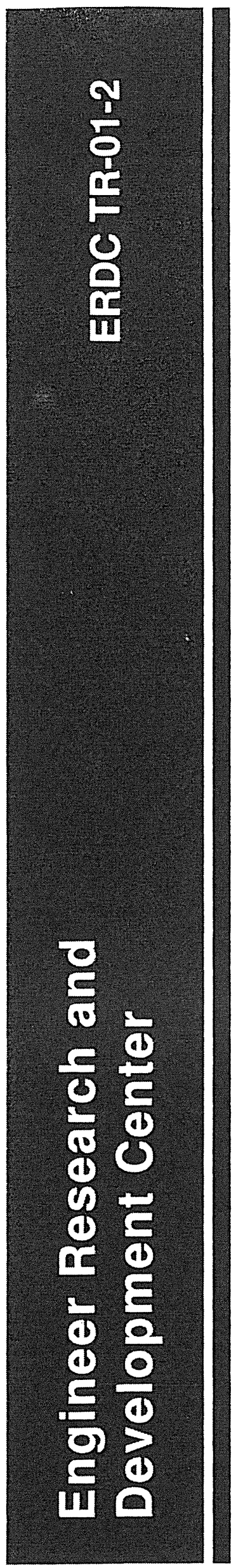

\section{Decision Support Capabilities for Future Technology Requirements}

Michael P. Case, William D. Goran, Thomas A. Gunther, January 2001 Jeffery P. Holland, Douglas M. Johnston, Gene Lessard, and Wayne J. Schmidt 


\section{Foreword}

This study was conducted for Headquarters, U.S. Army Corps of Engineers (HQUSACE) under RDTE Project 212040622720DO48, “Industrial Operations Pollution Control"; and Congressional Project Number 212040662720A917, "Computer-Based Land Management System." The technical monitors were Dr. Lewis E. Link, CERD-Z and Dr. Donald Leverenz, CERD.

The work was performed by the Coastal and Hydraulics Laboratory (CHL), and the Business Processes Branch (CN-B) and the Environmental Processes Branch (CN-E), of the Installations Division (CN) Construction Engineering Research Laboratory (CERL). Dr. Jeffery P. Holland, Special Assistant to the CHL Director, was the $\mathrm{CHL}$ researcher associated with this project. The CERL Principal Investigator was William D. Goran. Other CERL researchers were Michael P. Case and Wayne J. Schmidt. Thomas Gunther is associated with the U.S. Department of the Interior, Douglas M. Johnston is associated with the University of Illinois, Urbana-Champaign (UIUC); and Gene Lessard is associated with the National Watershed Coalition. The technical editor was William J. Wolfe, Information Technology Laboratory. Michael Case is Chief, CECER-CF-N, and L. Michael Golish is Operations Chief, CECER-CF. The Acting Director of CERL is William D. Goran.

CERL is an element of the U.S. Army Engineer Research and Development Center (ERDC), U.S. Army Corps of Engineers. The Director of ERDC is Dr. James R. Houston and the Commander is COL James S. Weller.

\section{Disclainer}

The contents of this report are not to be used for advertising, publication, or promotional purposes. Citation of trade names does not constitute an official endorsement or approval of the use of such commercial products. All product names and trademarks cited are the property of their respective owners.

The findings of this report are not to be construed as an official Department of the Army position unless so designated by other authorized documents.

DESTROY THIS REPOAT WHEN $\mathrm{T}$ IS NO LONGER NEEDED. DO NOT RETURN IT TO THE OAIONATOR. 


\section{Contents}

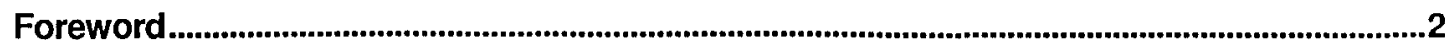

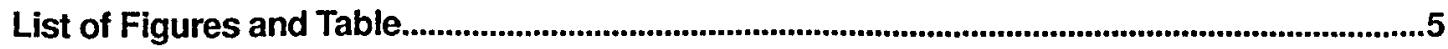

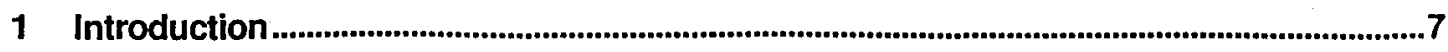

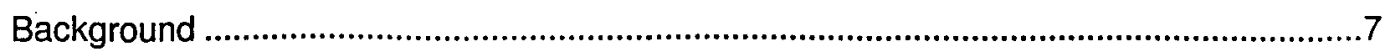

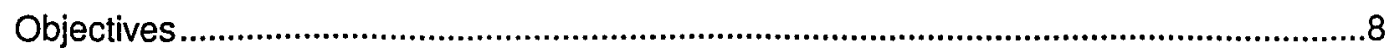

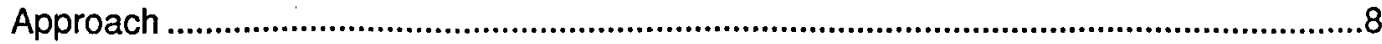

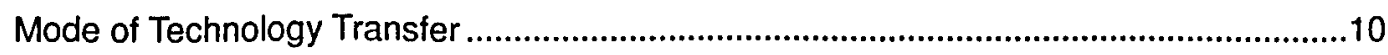

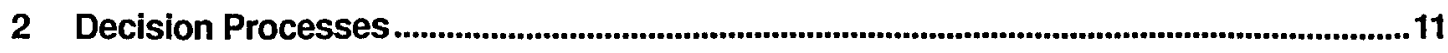

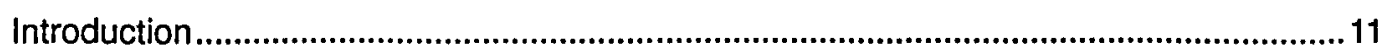

State-of-the-Art in Decision Processes....................................................................13

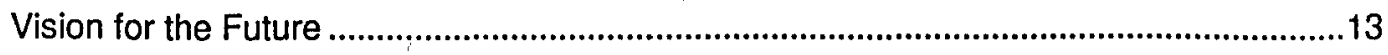

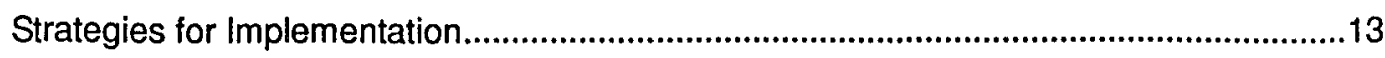

3 Collaborative Tools for Decision Support ..................................................................15

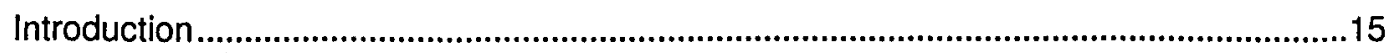

State-of-the-Art in Collaborative Tools and Decision Support .........................................15

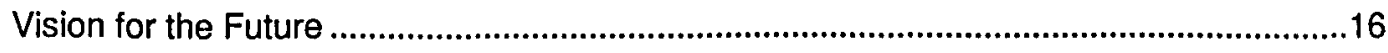

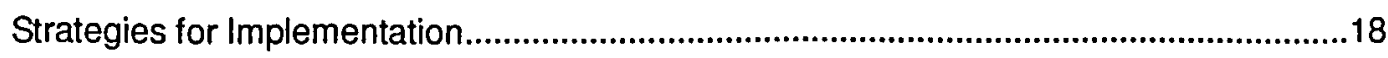

4 Information Management and Interoperability ................................................................19

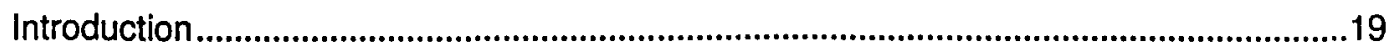

State-of-the-Art in Information Management and Interoperability .................................19

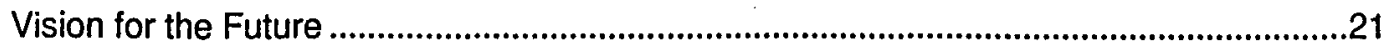

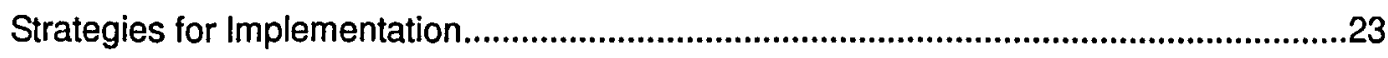

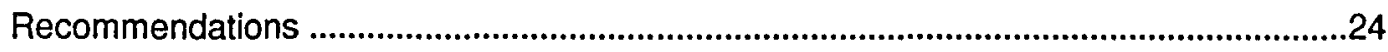

5 Knowledge Management and Decision Support...................................................................26

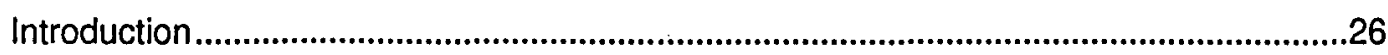

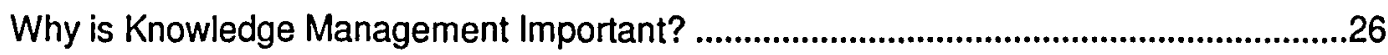

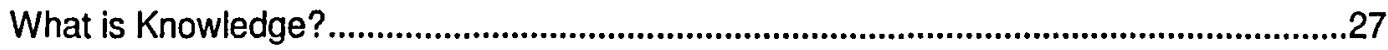

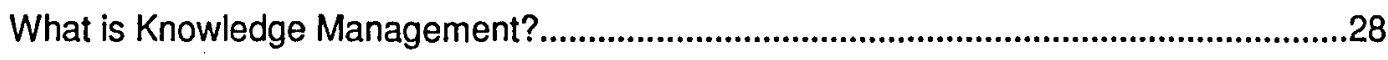

State-of-the-Art in Knowledge Management ............................................................28

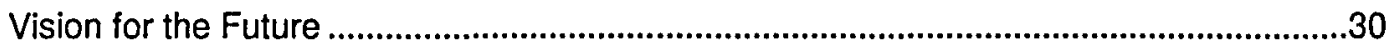




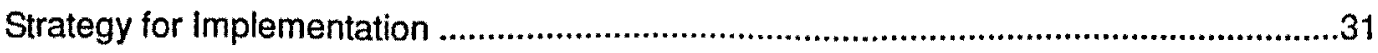

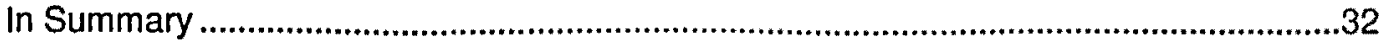

6 Computation, Communication, and Data Storage ..............................................................33

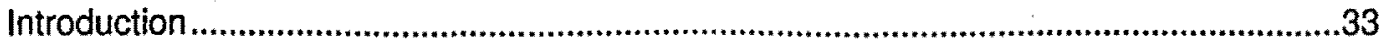

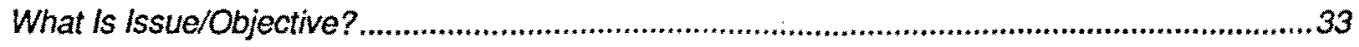

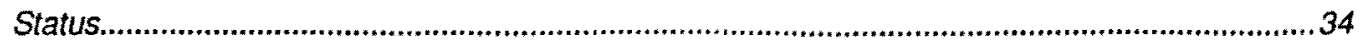

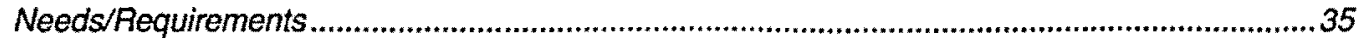

State of the Art Computation, Communication, and Data Storage ....................................35

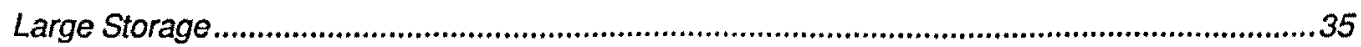

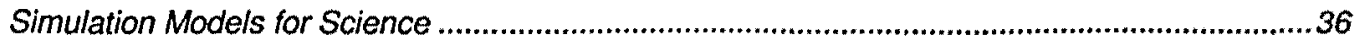

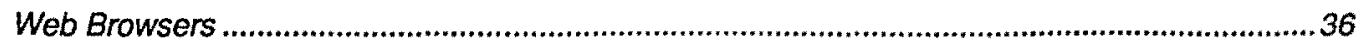

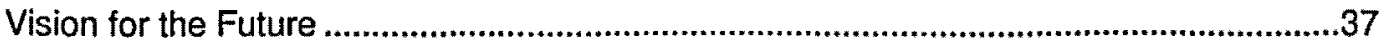

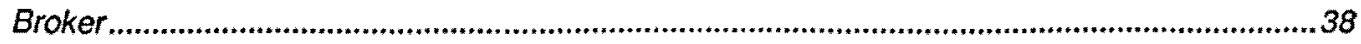

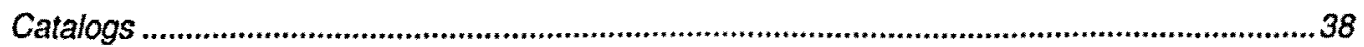

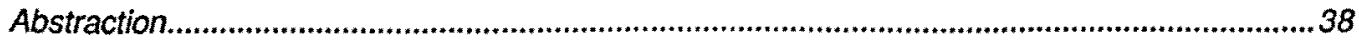

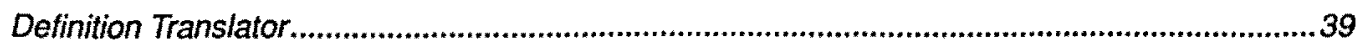

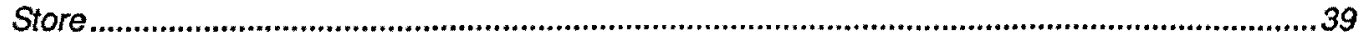

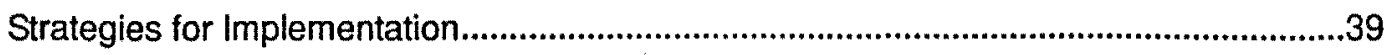

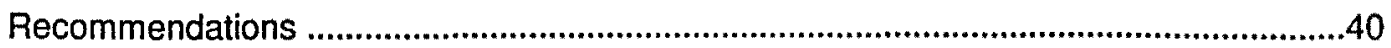

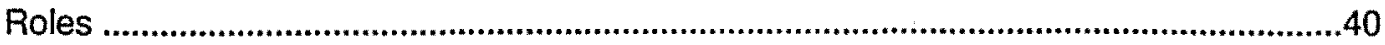

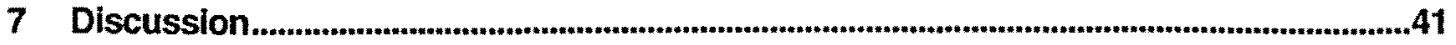

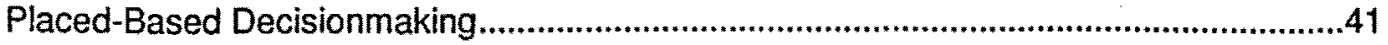

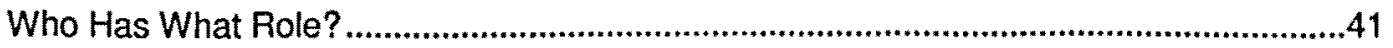

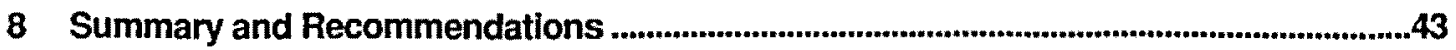

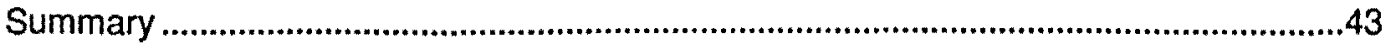

Recommendations ..........................................................................................46

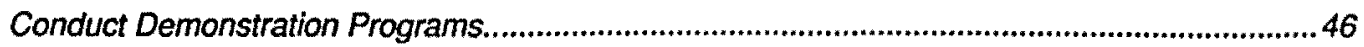

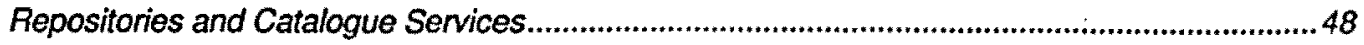

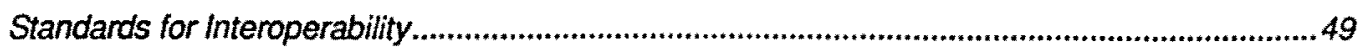

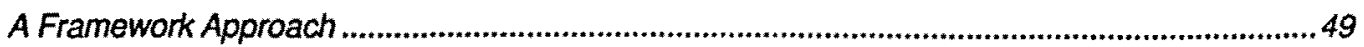

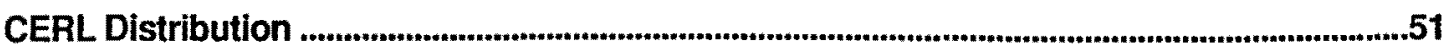

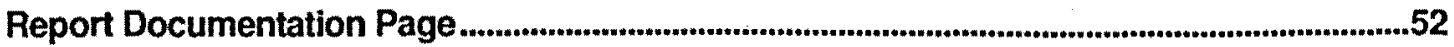




\section{List of Figures and Table}

Figures

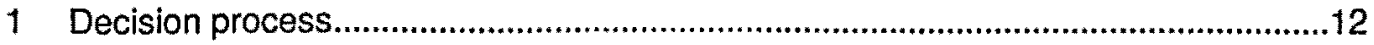

2 Conceptual view of information management and interoperability..........................20

3 Desired future state of information management interoperability ............................21

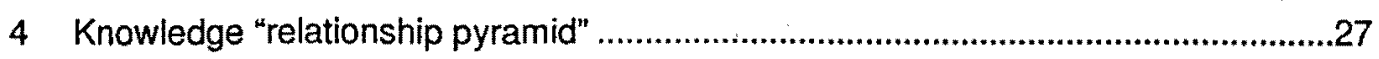

5 Technical ability in the decision support process...................................................29

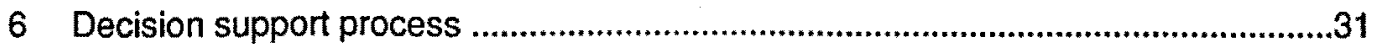

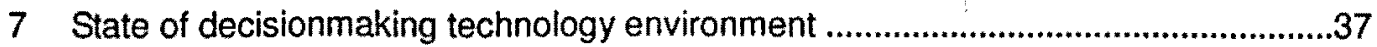

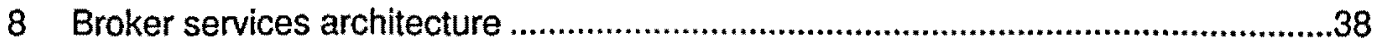

Table

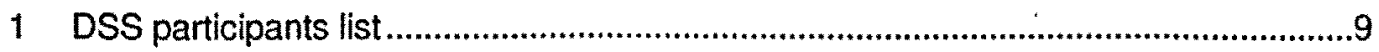

2 Participants and roles that shape improved future place-based decisionmaking......42 



\section{Introduction}

\section{Background}

Managing land ("place-based") resources has become a challenging task. Federal land resource managers are faced with complex decisions to balance goals of providing multiple land uses while complying with natural resource regulations, legislative requirements, inputs from sophisticated and often conflicting groups, and demands to accurately predict costs, benefits, options, and potential longterm, short-term, and cumulative consequences of any proposed management decision (and consequent action). The process for making decisions for "places" will become yet more complex and collaborative as land use intensifies, as land values increase, as more regulations are formulated, and as government authorities and nongovernment stakeholder groups multiply. Multiple authorities (such as drainage and watershed authorities, county boards, State and Federal regulators, and regional air quality managers) will need to negotiate with each other and engage stakeholders in these negotiations before they select a course of action (or inaction).

As the decisionmaking process becomes more complex, there will be increasing demands for technology to help decisionmakers explore and evaluate the issues, enhance communications in multiple media, identify and present relevant data, manage and refine processes, picture future options and outcomes, and channel participants towards endpoints and decisions. New technological capabilities will emerge from academic research, industry investments, and government experiments.

The Interagency Group on Decision Support (IGDS) was formed in 1997 to discuss decision-support tools, services, and other issues as they relate to natural resources and the environment. The IGDS has provided a forum for agency staff and stakeholders to meet and exchange information on currently available decision-support tools, to address concepts and principles of decision science, and to explore the potential for greater cooperation and coordination among users and developers. The Group's vision is to establish "a cooperative group of public and private stakeholders working together to build advanced systems for natural resource and environmental decisionmaking." This vision led to the establishment of the Aurora Partnership. 
The Aurora Partnership (URL: http:/www.aurorapartnership.org/) has a much greater reach than the IGDS. The Partnership is a collaboration of government, university, and private sector organizations. The approach of the Partnership is to engage in an open collaborative process to share ideas, information, and technologies to advance tools and systems that will enable the practical use of natural and social science in decisionmaking. The question posed by the Aurora Partnership is simply this-whether a conscious effort by an affiliation of academics, industry, and government can help to more rapidly and effectively shape and realize the potential advantages of these technologies. This work was undertaken to address and extend the goals and objectives of the IGDS and the Aurora Partnership.

\section{Objectives}

The overall goal of this work was to "stimulate the development and application of the next generation of information tools and systems for place-based management decisionmaking through the collaboration of public and private stakeholders." Specific objectives were to:

- improve the interoperability, modularity, and transferability of decisionsupport tools and services

- develop and apply decision science principles to place-based management decisionmaking

- incorporate both the decision science principles and tools into a science-based decision support framework.

\section{Approach}

This work reflects the outcome of one of a series of workshops aimed at addressing the goals and objectives of the IGDS and the Aurora Partnership. The organizing committee for this workshop included Thomas Gunther (USDI), William D. Goran (DOD), Thomas Hart (DOD), Kenneth Snyder (DOE), Gary Fisher (USDI), and Maury Nyquist (USDI). Table 1 lists all Decision Support System (DSS) participants.

The combination of new technological capabilities and growing demand generate greater expectations for decision support, and identify new challenges for developers and users alike. This workshop discussed challenges and opportunities to meet these expectations and to outline the next steps in a strategy for the next stage of Place-Based Decision Support Systems (PBDSS) development. This 
workshop specifically addressed several topical areas that the IGDS and the Aurora Partnership have identified over the past several years:

- decision processes

- collaborative tools for decision support

- information management and interoperability

- knowledge management and decision support

- computation, communication, and data storage.

Table 1. DSS participants list

\begin{tabular}{|l|l|}
\hline Name & e-mail \\
\hline Brenda Faber & Bfaber@foresite-net.com \\
\hline Peter Kenney & Peterk@usa.net \\
\hline Fred Limp & Fred@cast.uark.edu \\
\hline Paul Densham & Pdensham@geog.ucl.ac.uk \\
\hline Wayne Schmidt & Wayne.P.Schmidt@erdc.usace.army.mil \\
\hline Jeff Holland & Jeffery.P.Holland@erdc.usace.army.mil \\
\hline Robert Wallace & Robert.P.Wallace@erdc.usace.army.mil \\
\hline Kurt Buehler & Kurt@opengis.org \\
\hline Susan Crow & Scrow@esri.com \\
\hline George Leavesley & George@usgs.gov \\
\hline Jim Westervelt & Westerve@uiuc.edu \\
\hline Pat Black & Pbb@crrel.usace.army.mil \\
\hline Gordon Plishker & Rgs_gap@shsu.edu \\
\hline Darrell Nolton & Darrell.g.nolton@wrc01.usace.army.mil \\
\hline John Lambie & Jlambie@gte.net \\
\hline Mike Case & Michael.P.Case@erdc.usace.army.mil \\
\hline Bill Goran & William.D.Goran@erdc.usace.army.mil \\
\hline Maury Nyquist & Maury_nyquist@usgs.gov \\
\hline Tom Gunther & Thomas_gunther@os.doi.gov \\
\hline Ken Snyder & Ken_snyder@nrel.gov \\
\hline Steve Fine & Fine.steven@epa.gov \\
\hline Gene Lessard & Lessard@erols.com \\
\hline Kelly Dilks & Kelly.M.Dilks@erdc.usace.army.mil \\
\hline Janis Buchanan & Jbuchanan@mail.arc.nasa.gov \\
\hline Paul Turczynski & Pturczynski@autometrix.com \\
\hline Doug Johnston & Johnston@gis.uiuc.edu \\
\hline David Kirtland & Dakirtland@usgs.gov \\
\hline Allison Newcomb & Allison.A.Newcomb@erdc.usace.army.mil \\
\hline
\end{tabular}




\section{Mode of Technology Transfer}

It is anticipated that the themes emphasized by the workgroups will form the basis for demonstration programs focused (in part) on addressing specific local issues. Such demonstrations may be conducted within existing Federal, State, or privately sponsored programs, or could form a context for fashioning new programs. A clear additional goal of these demonstration programs would be to leave a legacy of capability within the community that will be applied to future issues. 


\title{
2 Decision Processes
}

\author{
by Thomas A. Gunther
}

\section{Introduction}

Decisionmaking is the result of a sequence of implicit or explicit steps (Figure 1, adapted from Dave Cleaves' Report on the Decision Support Systems Workshop [USGS, May 1999]). One's awareness that a decision must be made begins with the recognition of a problem or an opportunity, or sometimes just with a vague awareness that some condition or thing could be improved. In this representation, process mapping, problem framing, intelligence gathering, evaluating and choosing alternatives, and learning from the outcome follows recognition. Of course, the activity or experience at any one stage-say intelligence gatheringcan alter the outcome of an earlier stage, in this case, perhaps problem framing. Indeed iteration through such "feedback loops" is essential to "good" decisionmaking. Iteration allows new information, knowledge, and ideas to be incorporated, and permits adaptive management. "Good" decisions are at least partly a function of the time and effort expended on the process as a whole, and on each of its stages.

The process of making decisions also varies with the type of decision to be made and the number of decisionmakers involved in the process. Some decisions, such as those covered by the National Environmental Policy Act (NEPA), must follow procedures established by law and must be well documented. Some decisions depend on data delivered by real time sensors or experiments, and thus require rapid integration of data and models to meet management needs. Other routine management decisions simply pertain to operations or maintenance. Some decisions, usually affecting longer-term plans, require the collaboration of a range of stakeholders, who often enter the process with conflicting goals and objectives.

These three aspects of decisionmaking-the process, the type of decision, and the amount of collaboration necessary-constitute the environment in which decision support tools and systems will be used. The same set of tools may provide support for different types and stages of decisionmaking, but may be applied in different ways, with different intensity, and with different requirements for precision and presentation. 


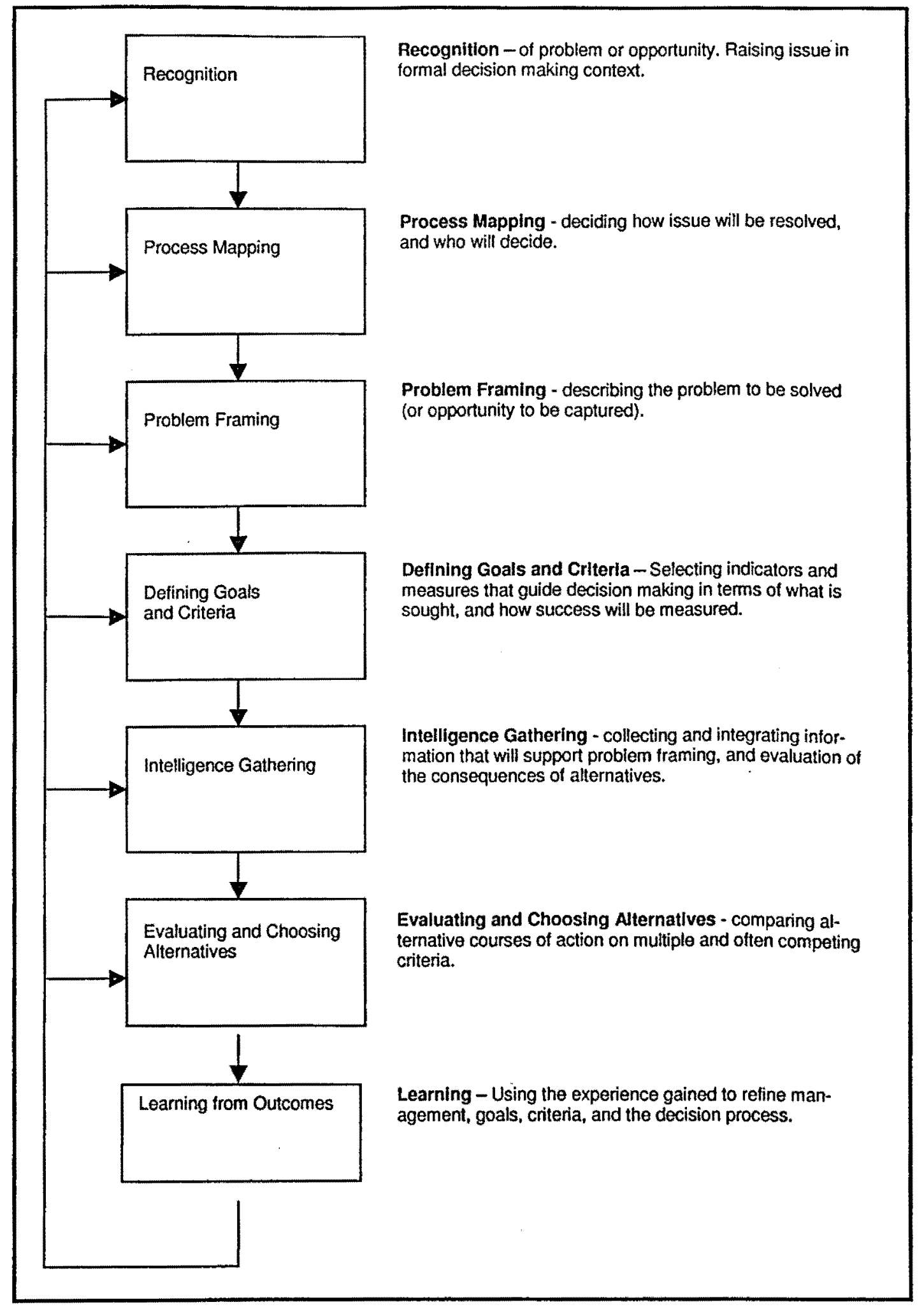

Figure 1. Decision process. 


\section{State-of-the-Art in Decision Processes}

Decision support tools and systems cannot supplant the decisionmaking process. However, an increasing number of increasingly sophisticated computerized tools can provide assistance. There are tools to help brainstorm, discover and measure preferences and performance, poll participants, facilitate and manage meetings, and provide a formal record of the process. There are other tools to assist in understanding and displaying the impacts of proposals, including the trade-off among various criteria with different alternatives, changes in the way an area will appear, and other often nonquantifiable changes in the quality of life. But many of these tools come from different specialties, disciplines, or developers. Individual tools tend to focus on relatively narrow issues. Such tools are developed and used independently of each other. Moving data, stakeholder input, models, and results from one tool to another can be difficult or impossible. Even if a community is aware of the range of tools that can assist them in making decisions, the tasks of assembling, learning, and applying tools puts these capabilities beyond the reach of most users.

\section{Vision for the Future}

A manager, group, or community would have a toolbox containing a variety of tools to help address the range of place-based problems. Some tools would assist in understanding and improving the process itself. Others would assist specific stages, such as intelligence gathering or evaluating alternatives. Still others would help identify very specific tools for specific problems or parts of problems (e.g., hydrologic models). New tools could be added as new problems arise or as conditions change, without the need to extensively modify or replace either the toolbox or existing tools. The interface would be consistent, and learning about the capabilities of the toolbox and the geographic area being considered would be cumulative. The toolbox would be one of many offered by different vendors, and all would be capable of incorporating tools from other sources.

\section{Strategies for Implementation}

Several specific steps should be taken to improve support for the decisionmaking process. These steps are intended to increase user awareness of existing tools (whether or not they are designed for place-based management), and move toward the concept of integrated toolboxes: 
1. Develop and inventory tools that can help assess decision processes (rather than decisions). In most cases, these tools will be in the form of paper guidelines. Is the range of stakeholder goals and values identified and reflected? Have criteria for selecting among alternatives been established and are performance measures selected?

2. Inventory computerized tools that are currently available and which, with some modification, can aid in decisionmaking. Examples include "groupware," tools to elicit preferences and weights, project management software, and visualization programs. These tools were typically developed for different applications (such as software development), but have many capabilities important to place-based management.

3. Initiate a "Request for Information" for PBDSS tools and systems, and begin a multi-agency evaluation and analysis of these tools and systems.

4. Develop a set of guides (probably through a World Wide Web site) to the process and the currently available tools and systems. Identify specific tools for different stages of the decision process.

5. Develop a set of case studies and/or other "lessons learned," including evaluations of tools and applications, meta-analyses, and retrospectives on past place-based activities.

6. Initiate a series of linked demonstration projects, each of which will be designed to improve the support for the decision process. 


\section{Collaborative Tools for Decision Support}

by Michael P. Case

\section{Introduction}

In today's public and private decision environments, many choices formerly made by individuals are made by groups of people. In addressing the question of how collaborative tools might help these groups, it is important to recognize that effective collaboration is primarily a social process that requires an understanding of human behavior. In the "place-based" decision arena, collaboration tools can help in two important ways. First, they can serve as tools to apply proven group decision support methods and processes. Second, they can serve as an aid in helping group members to arrive at a shared understanding of technical information relevant to the issues under consideration.

Effective collaborative tools should help stakeholders in a decision process arrive at better decisions when measured against metrics of consensus, awareness, representation, time, and/or cost. Collaborative tools may help groups to develop shared understanding of issues, evaluate alternative solutions, build consensus, or resolve disputes. Tools may also be used to break down barriers of time and space in communication between stakeholders. In addition to the traditional "town meeting" venue (synchronous and co-located), tools allow collaborators to work at their own pace (asynchronous) and own place (distributed). Although it is generally recognized that the bandwidth of human communication is greatest in face-to-face meetings between stakeholders, the asynchronous and distributed capabilities offered by automated collaborative tools can act to augment limited resources of time and funding.

\section{State-of-the-Art in Collaborative Tools and Decision Support}

The current status of collaboration tools encompasses both traditional and electronic media. Place-based decision support requires proactive efforts to meet with stakeholders and solicit involvement. Techniques such as focus groups, 
breakout groups, flip charts, and "place-the-dot" style voting are commonly used techniques. Despite their low level of technology, they may still be considered state-of-the art.

Electronic media has enhanced rather than replaced many of the manual methods mentioned above. Tools such as e-mail, mailing lists, chat rooms, web servers, and discussion forums are all examples of on-line technologies that ease the process of distributing information and exchanging points of view. Online meeting tools such as Netmeeting and $C$ - $U$ See $M e$ offer new ways to overcome barriers of time and distance through video teleconferencing and application sharing.

The class of tools commonly called Group Decision Support Systems (GDSS) provides utilities to help elicit viewpoints, generate ideas and discussion, and build consensus. Typically, such systems are set up in a dedicated room where participants each have their own screens and keyboards. Meetings may or may not be facilitated and input may or may not be anonymous.

A final class of collaboration tools gives collaborating groups an online location to keep shared documents and data. These tools offer electronic document management functions, communication utilities for members (forums, chat, etc.), and shared visualization of graphics (CAD, GIS, images). These tools are readily available over the Internet and accessible through web browsers or client software. Discipline-specific varieties of these tools add features needed to perform tasks unique to a discipline. For instance, software configuration control tools offer utilities for version control and defect management.

\section{Vision for the Future}

How can collaboration tools help to improve the effectiveness of place-based collaboration? To answer this question one should first examine some impediments to effective collaboration, and explore some strategies to overcome them. Having done that, some ways in which tools can help implement these strategies will become apparent.

1. Competition. People and organizations (stakeholders) have valid reasons to compete for funds, space, resources, recognition, or other goals. Collaboration is impeded by a lack of common goals. Win-win strategies are desirable, but not always possible.

2. Turf. Stakeholders seek control over decisions that affect them. A real or perceived loss of control may impede collaboration. 
3. Stovepipes. Organizational boundaries of responsibility, accountability, and authority may prevent collaboration.

4. Efficiency. Developing consensus among all involved stakeholders can be difficult and lengthy process. Sometimes it appears easier to work alone or in small groups. This can be an unfortunate strategy when stakeholders that were not considered put up road blocks (see \#5).

5. Identification of Stakeholders. Sometimes it is very difficult to recognize who the stakeholders are in an issue. Late involvement of stakeholders sets back the collaboration process.

6. Purpose. Members of a group may not always have a shared understanding to the desired outcome of collaboration.

7. Process. Lack of buy-in to process and tools can inhibit collaboration.

8. Knowledge and Skill. Stakeholders may bring very different backgrounds, skills, and understanding to a problem. Some may not understand important social or technical issues.

9. Resistance to Change. Some stakeholders may be more comfortable with maintaining the status quo.

10. Resource limits. Collaboration requires an investment of resources (i.e., time, personnel, energy, and funds).

Given these typical impediments to collaboration, how can automated tools provide assistance? In the desired future, strategies and tools will be available to develop shared purpose, to develop shared understanding, and to provide resources. These three goals are:

- To Achieve a Shared Purpose. Although stakeholders may have conflicting goals, it is important that these goals be articulated and expressed. Only then can a group work towards achieving an acceptable solution. Resources will be available that will help groups to achieve a preferred future focus. Rather than concentrating on overcoming problems, proven decision support strategies are available that can help groups to develop and realize a shared vision. Group Decision Support (GDSS) Systems, Computer Supported Collaborative Work (CSCW) Tools, and lessons-learned systems can assist in overcoming impediments $1,2,3,4,5,6$, and 7 .

- To Achieve a Shared Understanding. Work in the social sciences shows that groups must work through a process of developing a shared understanding of issues. This is especially critical when technical issues or jargon are involved. Tools that can help illustrate the meaning of highly technical analyses to people of disparate education and backgrounds will help groups to achieve shared understanding more quickly. For example, visualization and 
simulation using GIS, 3D, and $4 \mathrm{D}$ (where time is the fourth dimension) are very effective in communicating complex ideas and consequences. Impediments 6,7 , and 8 are affected.

- To Provide Resources. Traveling to meetings, arranging schedules, or retrieving obscure information all require time, money, and personal motivation. Web-based tools that improve access to materials, information, and other stakeholders will lower resource-driven barriers. Home, civic, or regionallyoriented information resources can make it easier for local citizenry to research issues on their own time and schedule. One suggestion is to set up resource centers in libraries or local schools. Readily available electronic meeting rooms will provide virtual locations for people to meet. Public access sites to these virtual resources will help increase usage. Achieving this goal will affect impediments 5,8 , and 10 are affected.

\section{Strategies for Implementation}

Many tools are already available that will help achieve the desired future. The recommended strategy is to focus on the establishing a national center or centers that will coordinate a small number of test bed programs while providing collaborative implementation toolkits to groups that are interested in experimenting with place-based decision support. An alliance of Federal and State agencies, standards organizations, vendors, and consultants should pool resources on a voluntary basis to:

- encourage local centers for Place-Based Decision Support

- act as a repository and resource for "best practice" process templates

- act as a repository and resource for lessons learned

- provide free or low cost visualization, modeling, and scenario generation tools

- fund a small number of pilot demonstration programs.

Resources from this alliance would be available on the condition that the organization or individual using the resources provide lessons learned or add to the knowledge base of process templates. 


\title{
4 Information Management and Interoperability
}

\author{
by Jeffery P. Holland
}

\section{Introduction}

Information management involves the purposeful, directed manipulation of data as it moves from information (e.g., inputs for decisionmaking) to knowledge (e.g., belief and value sets used as overarching constraints, goals, and objectives in decisionmaking). Data are formatted, evaluated, and distilled in the process of becoming information (Figure 2). Information is evaluated, integrated, and applied in the process of becoming knowledge.

Interoperability (" $I$ " in Figure 2 ) is the capability of productively and seamlessly moving from data to information to knowledge, and back, in a manner whose infrastructure is transparent.

\section{State-of-the-Art in Information Management and Interoperability}

The current state of practice for information management and interoperability is:

- Developing Standards Poorly Used. Several groups are developing (or have developed) standards that will strongly facilitate interoperable information management. These groups include:

- OGC - Open GIS Consortium

- ISO - International Standards Organization

- FGDC - Federal Geodetic Data Committee

- Industry - through the organizations above and through marketplace activities related to commercial product development.

Clearly, there are a number of existing and oncoming efforts at developing standards. However, the use of these standards is highly nonstandard between, and within, major organizations. 


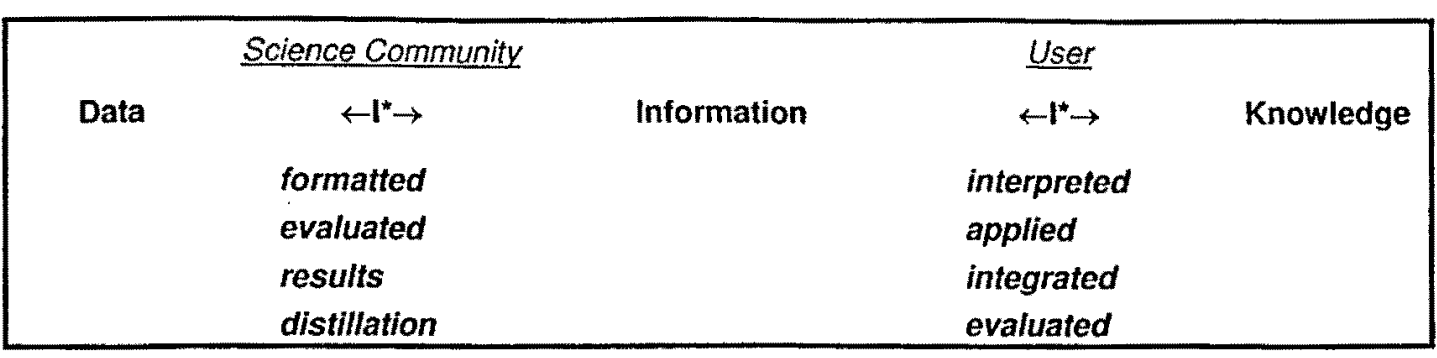

Figure 2. Conceptual view of information management and interoperability.

- No Money to Apply Standards. Many organizations do not yet appear to be adequately resourcing the use of standards in their activities. This seems particularly true of efforts to reformulate existing software and databases within new standards contexts.

- Middle-Ware Development. Significant strides have been made in the development of middle-ware to support interoperable information management.

- Proprietary Solutions. A number of in-house proprietary methods for achieving interoperability within a given organization or element do not translate across the information spectrum.

- Emergence/Development of Cross Cutting Formats. Several data/information formats (e.g., XML, GML, JAVA, etc.) are emerging that offer significant promise in supporting interoperability. However, these technologies have not been fully implemented.

Understanding the role of each of these items requires one to have a broader grasp of the current state of users of data, information, and knowledge:

- Generators vs. Users. There is a significant difference in the expectations of, and capability for, information management between generators of information (e.g., the scientific and engineering communities) and the users of information (e.g., decisionmakers, the public, etc.). This involves all facets of information flow (Figure 2).

- The Internet has Raised the Level of Expectations. Users from all levels of sophistication now believe that data, information, and knowledge should be available at their fingertips through the World-Wide Web. This raises the level of expectation regarding the productive use of the Internet in reaching information.

- Institutional Barriers. Institutions often have a "not-invented-here" philosophy that acts as an impediment to the use of standards that affects interoperability.

- Lack of Reward. There are limited financial incentives for industry to develop interoperable marketplace solutions. Further, there is a perception 
within government organizations that interoperability is a luxury rather than a requirement for sound management.

- Lack of Standards Across the Board. There are still major technological areas that have not as yet promulgated data/information standards.

- Output Definition. As a follow-on to the "Generator vs. Users" bulleted item above, there are requirements for the output of data/information in highly different ways to meet the specific needs of a given group of stakeholders. This involves multiple issues of information management and interoperability so users can obtain the output type(s) of choice.

The bottom line is that there is a lack of interoperability as one goes back and forth through the data-information-knowledge spectrum shown in Figure 2

\section{Vision for the Future}

The desired future is one of information management services that are fully interoperable across-the-board, and that are available to the broadest range of stakeholders possible. Figure 3 shows the desired information environment. The desired future involves seamless movement of data, information, and management from research to analysis to synthesis to adaptation. This is particularly true in the decision science area where new science findings must flow to implementation, and where feedback produces the need for adaptation of a given management decision.

\section{Science \& Art of Decision Process}

incorporation of data management and interoperability

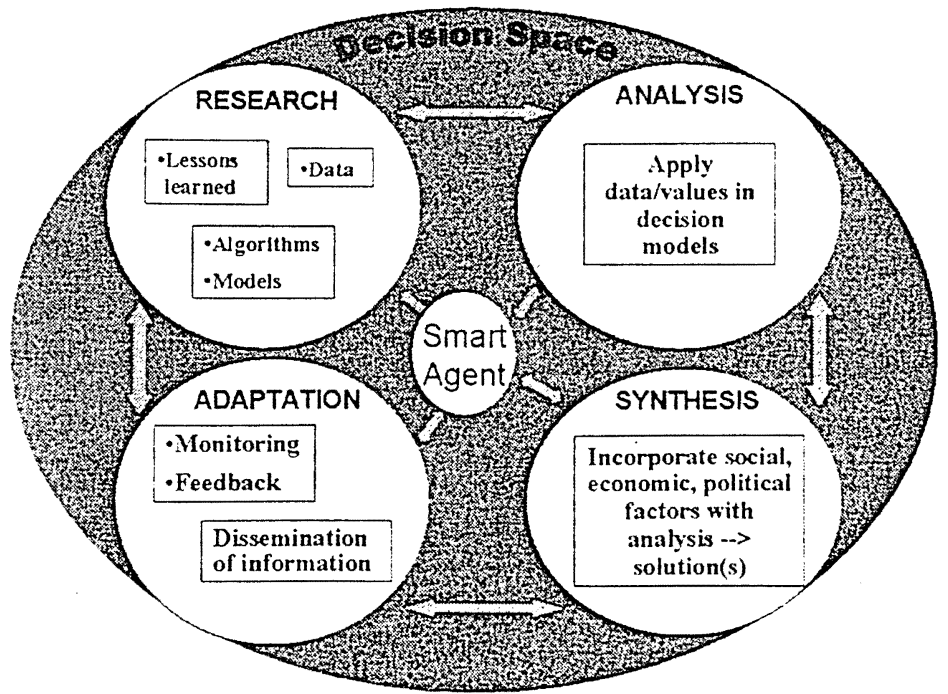

Figure 3. Desired future state of information management interoperability. 
Toward this end, five areas are viewed as desired levels of functionality for future interoperable information systems:

1. Access. Differing stakeholders should be able to use different components of an interoperable information system from their geographically-distributed desktops.

2. Catalog. The system should provide for a repository for techniques/algorithms in a standard, web-searchable form.

3. Smart Agent / Knowledge Management. Methods should be developed to capture the knowledge base, sharing "lessons learned," "decision model," "case studies," etc. for repositing in the cataloging framework above.

4. Motivation. Develop mechanisms that strongly encourage the development of inhouse and marketplace interoperable solutions.

5. Processing. Encourage the interoperability and reuse of tools through standards.

The desired future would have the following goals/objectives/features:

- All data would have standardized repository by data type.

- Users would obtain and manage data via integrated problem solving environments.

- Interoperability and reuse of tools would be promoted through the consistent use of standards.

- Smart agents would facilitate input requirement, tool selection, and results analysis.

- Computational environment would facilitate sharing "lessons learned," "algorithm," "decision model," and "case studies."

- Repository/tracking of decision process would be facilitated through a problem-solving environment.

- Information management would use one set of national interoperability standards.

- Financial incentives would encourage contractors/vendors to use standards set in place.

- Information services would be designed to eliminate noninteroperability ("not invented here").

- A higher conceptual or natural language query capability would facilitate decision support to many stakeholders.

- New technology implementations would be transparent to the user.

This set of goals/objectives/features would apply across the spectrum listed in Figure 2. This alone would promote interoperability in a meaningful way. 


\section{Strategies for Implementation}

The desired future is achievable through strategic implementation activities as listed below. Note that this list is incomplete both in scope and in specifics. However, it is clear that the proposed implementation strategy includes marketplace, organizational, technical, and programmatic factors, any of which can frustrate convergence to the desired future state. The implementation concepts are keyed to the desired future state bullets listed above.

- All data would have standardized repository by data type. Develop open "wizards" that facilitate placing data within web-accessible repositories. Define these repositories using standards as well so that they can be queried and mined by different users who see them as virtual repositories.

- Users would obtain and manage data via an integrated problem solving environment-a consistent, integrated problem solving computational environment. Major Federal government organizations and industry should collaborate to provide the critical mass needed to properly develop the environment. Note that this is not to suggest the development of a single environment with one look and feel, but a global environment with a user-customizable toolkit that builds from a common set of information technologies and standards.

- Interoperability and reuse of tools should be promoted through the consistent use of standards-this goal can be realized through the use standards, development of repositories, development of the problem solving environment listed above, and through several of the items listed below.

- Smart agents facilitate input requirement, tool selection, and results analysis. Develop a standard set of agents, acting behind the scenes over a network or the web, to facilitate data/information creation, location, and retrieval, model/tool selection, visualization, etc. These agents would be "freeware" to ensure broad-based use.

- Computational environment facilitates sharing "lessons learned," "algorithm," "decision model," and "case studies." This would be an extension of the user environment above to some extent, but would also employ smart agents and the creation of publication standards to mine and reposit new findings and information into repositories in object formats.

- Repository/tracking of decision process would be facilitated through a problem solving environment. A new set of smart agents or wizards should be established to monitor and feed back the actual processes used in decisionmaking for a given situation.

- One set of national interoperability standards should be adopted. This should be an established, focused, directed, and funded objective of the major Federal agencies, with incentives to industry, to ensure that one national set of standards is created. The referenced incentives are needed to ensure that 
these standards become the marketplace standards, and to ensure their lifecycle use and implementation.

- Contractors/vendors should receive financial incentives to use standards. Major procurement organizations (e.g., government) should provide financial incentives through contracts to promote (or require) the use of established standards. Other marketplace incentives, such as the use of cooperative agreements combining government and private funding to develop standards, should be employed.

- Eliminate designed noninteroperability ("not invented here"). Promote the use of standards through Agency order at the national or agency level.

- Provide a higher conceptual or natural language query capability to facilitate decision support to many stakeholders. Develop the means for decisionmakers to query data of all types (including modeling and simulation data) using terms (language) they understand and identify with.

- Make new technology implementations transparent to the user. This would be done primarily through the use of object-oriented, modular developments, and through the use of standards/agents as listed above.

In addition to the points raised above, it is essential that a paradigm be established that encourages the differing stakeholders within the decision process to conduct the activities at which they excel rather than all the components of the process per se. For example, the development of an interoperable information technology architecture envisioned might cause one to conclude that decisionmakers with limited technical background could simply go to the web, access data, execute models, and perform visualization at will. This should not be either the expectation or the goal. Rather, the interoperable model presented above should be used to facilitate the interactions between experimentalists, modelers, integrators, analysts, managers, and the public, rather than to replace said interactions. Toward this end, it is essential that the process of creating the envisioned interoperable environment also include checks and balances that facilitate the science and engineering community's verification of tools, models, or methods before their use by decisionmakers, and that stakeholders have the opportunity to directly frame the use of said tools in deciding alternative futures for a given site.

\section{Recommendations}

It is tempting to recommend simply that the items listed above that are required to achieve the desired future, be funded and conducted as presented. However, there is significant investigation and discovery left to conduct to understand the best ways to implement the goals/objectives listed above. 
Toward that end, it is recommended that a series of highly-focused technology demonstrations be created and conducted that, by design, investigate the best of several means for achieving interoperable information technologies. Envisioned is a set of five to seven demonstrations, chosen to reflect differing natural and water resources decision processes, each with differing stakeholder requirements, that exercise the differing interoperability and information aspects listed above. It is recommended that the Federal government agencies with major roles in the natural and water resources area come together to establish these demonstrations in direct concert with stakeholder groups and industry. The time period for the demonstrations should be no more than 2 years. 


\title{
5 Knowledge Management and Decision Support
}

\author{
by Wayne J. Schmidt
}

\section{Introduction}

An old proverb says, "If I have only a hammer, the world looks like a nail." As the number and complexity of environmental analysis tools grows and the decision process become more complex, it becomes increasing difficult to keep current on the best methods. This chapter envisions how the emerging field of knowledge management can be used to assist in the applications of analytical tools, data representation, and modeling to help the user solve problems related to natural resources and the environment. This chapter describes the current state of the art for knowledge management, a vision of how knowledge can be managed to support natural resource and environmental decisionmaking, and a strategy for demonstrating the vision.

\section{Why is Knowledge Management Important?}

The term "Knowledge Management" (KM) has become a key issue for government, industry and certainly Information Technology (IT) executives. Organizations are becoming increasingly aware of the importance of managing knowledge, like any other asset, to improve their competitive advantage. Careful application of knowledge, like other assets, can result in better decisions particularly, at the working level. Typically, there is a wide variety of analytical tools available. The users' dilemma often becomes one of managing the entire decision support process. the issue may be restated as a question: "What is the sequence of tasks that will reliably produce the report/documentation to support the conclusions reached?" 


\section{What is Knowledge?}

Before one can talk about knowledge management, it is useful to have an understanding of how knowledge differs from information or data. Peter Drucker defines knowledge as "Information that changes something or somebody-either by becoming grounds for actions or by making an individual (or an institution) capable of different or more effective action."

Knowledge is the result of aggregating process, information, analysis, and supporting documentation into a package that will support a conclusion. It is the end result of combining these factors and our experience. The concept of transforming data into information is well known and understood. This concept can be extended to characterize knowledge as part of a relationship pyramid (Figure 4). The pyramid illustrates how:

- Data in context yield information.

- Information after analytical effort yields understanding.

- Understanding when combined with professional judgment yields knowledge.

- Knowledge in turn supports decisionmaking.

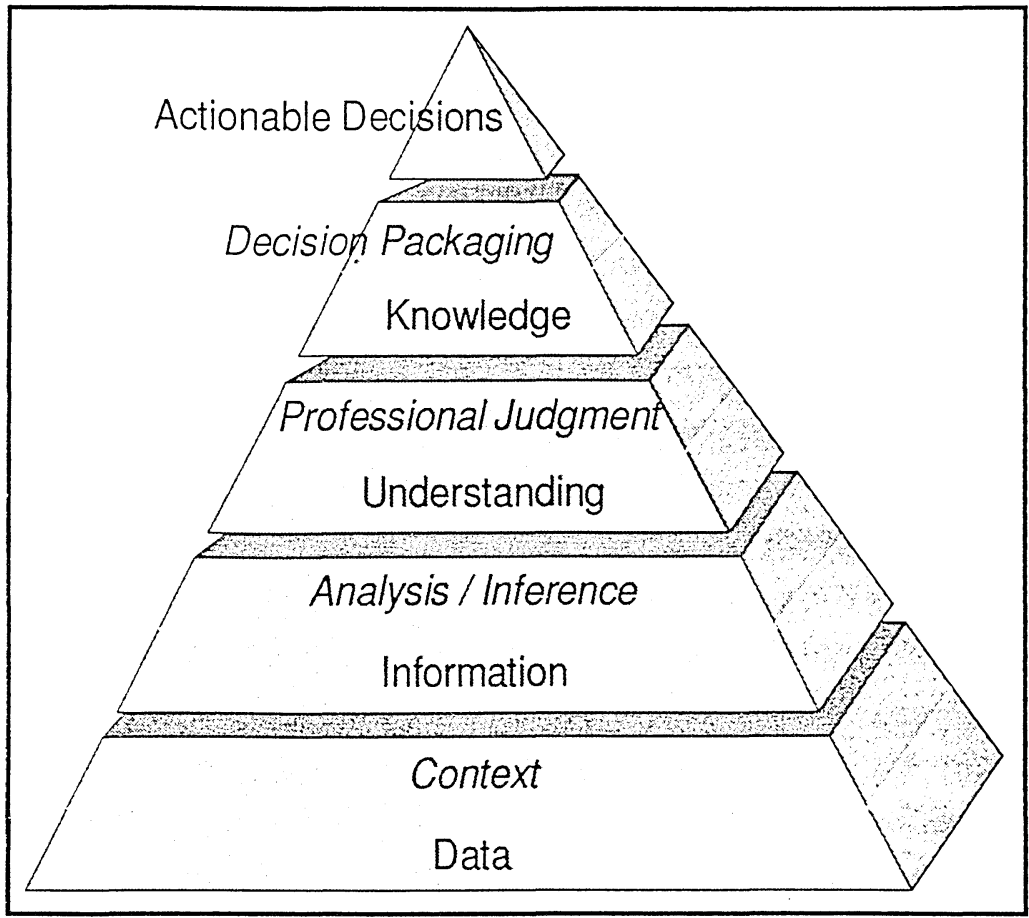

Figure 4. Knowledge "relationship pyramid."

A wide variety of analytical tools are available. Such tools help the user move from information to understanding. Information/data is processed and displayed in a variety of forms, and is analyzed by various models to present data in a way that can be easily understood. While this is an important part of the entire deci- 
sionmaking process, many other tasks must also be accomplished. For example, data must be gathered, presentations made, reports done, decision papers authored, executive summaries written, public announcements made, etc. All of these tasks are part of the knowledge that must be managed to help the user complete the decision process.

\section{What is Knowledge Management?}

Knowledge Management is an integrated, systematic approach to identifying, managing, and sharing an enterprise's information assets, including documents, databases, policies, procedures, and implicit expertise. The purpose of this integration is to make available the validated "Decision Support Process" that will guide the user to the decision point. In many organizations this Decision Support Process is well understood for a particular class of problems. However, when new problems arise, or when institutional knowledge is lost due to retirement, transfer, etc., effectiveness suffers while the process is relearned.

The level of technical ability of stakeholders within the decision process (Figure 5 ) is often very different. The citizen will have the least technical ability to understand and manipulate the data. The decisionmaker has a better understanding, the engineering staff has still more, and finally the research modelers have the best understanding of the data. However, the researcher is removed from the decision process and is often solely concerned with analysis. The users in the shaded area are the intended users of a knowledge management capability. They understand the nature of the decision, but do not have the knowledge to plan and manage the Decision Support Process. In short, they need a knowledge management capability.

\section{State-of-the-Art in Knowledge Management}

Knowledge management, while the subject of many conferences, books, papers, and tools, is immature. There are tools that accomplish some knowledge management, but do not address the entire concept. 


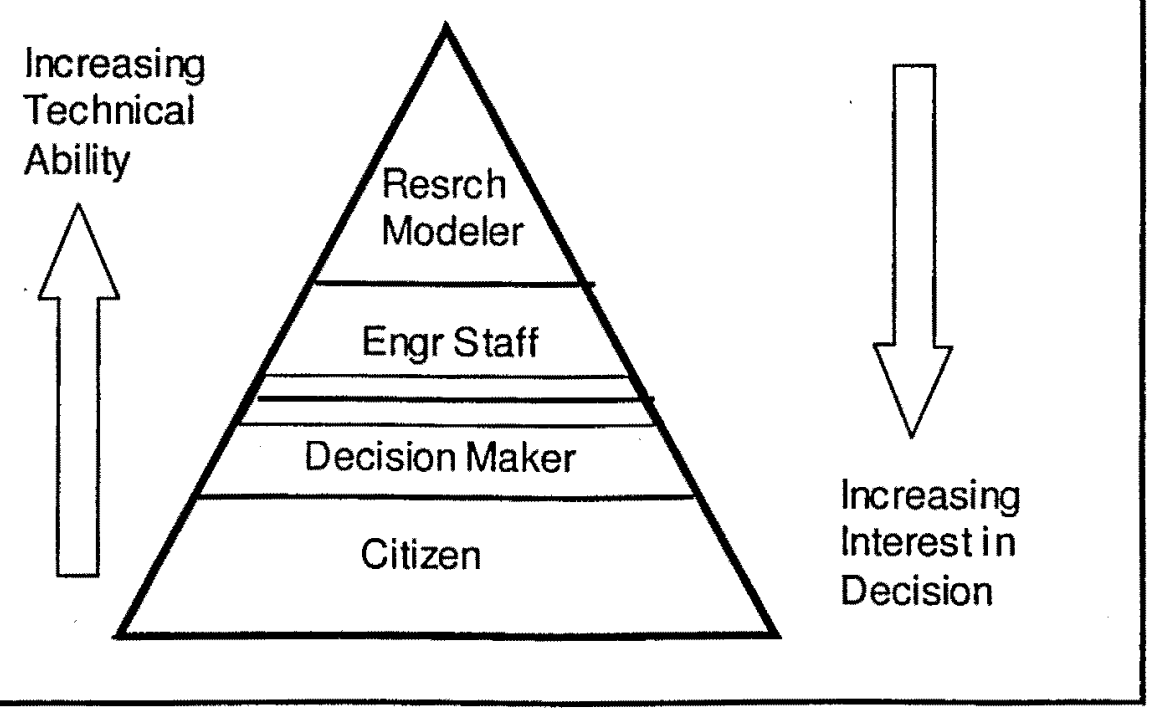

Figure 5. Technical ability in the decision support process.

Traditionally, libraries provide the knowledge management function. Libraries store the accumulated knowledge of the ages. The time-honored way, especially in the scientific community, is to make knowledge explicit by publishing. However, most scientific literature is very technical and only useful to other scientists, not to problem solvers. Such knowledge also deals with theory, not with the tasks required to complete the decision process. In addition, this literature is paper based and difficult to reuse.

The publishing process is long and resource intensive. It is seldom used in the business world and notably not used to make the business process explicit. Some businesses publish "Standard Operative Procedures" and "Policies." Keeping these printed documents current is a resource intensive problem. Thus, the documents become obsolete and fail to be effective sources of knowledge. Again, they are usually paper-based.

Many tools are available to deal with parts of the knowledge management problem. These tools are often called knowledge management "solutions," but they only address part of the problem. For example, there are very complex search engines that will search the web, stored documents, email, and even data bases. But they do not address why the user wants this information, where it fits within the decision support process, and where an approved method of reaching a conclusion exists.

The technologies for Knowledge Management revolve around implementing the KM Process. Each of the stages has existing technologies, although many are 
marketed under the global "knowledge management" title. Some technologies span several of the stages, but addressing the entire spectrum requires careful thought and planning. The existing technologies include:

- Process Development:

- IDEF models (approved Federal Government Standard)

- Rummler-Brache

- Search:

- Search engines (Infoseek, web crawler)

- Information portals (Yahoo, AltaVista, DogPile)

- Databases (e.g., Lexis-Nexis)

- Information Systems (GIS)

- Data mining and warehousing

- Expertise tracking and locating

- Organize:

- Decision Support Systems

- Word processors

- Knowledge Mapping

- Workflow

- Create:

- Group Decision Support Systems

- Collaboration Portals

- Discussion groups

- Video Teleconferencing

- Storytelling

- Capture:

- Peer review

- Cataloging and indexing

- Business practice repository.

- Documents designed for retrieval by coding content (XML).

\section{Vision for the Future}

Any vision for knowledge management must be focused on a user community. In this study, the "knowledge management vision" was adopted from the perspective of the user community described earlier. Thus, the vision is: "A searchable distributed library of Decision Support Processes (DSP)." Each DSP is a complete "case study" of the process, data requirements, analytical tools, and report examples necessary to propose and support decision alternatives (Figure 6). 


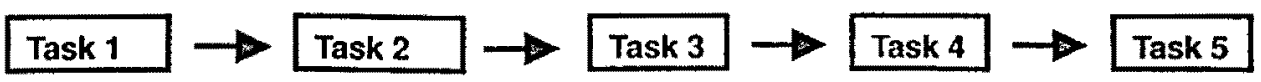

Figure 6. Decision support process.

A DSP is a linked set of tasks that describe how to achieve a solution. Some of the tasks will require manual action, e.g., "coordinate with the EPA." Others will require the use of word processors, e.g., Develop a status statement for the public affairs office." Still others will suggest specific tools to accomplish data analysis. Each DSP has these attributes:

- decision/problem addressed

- description

- where used and when

- developer of the DSP

- relevant policies

- tools used

- start conditions

- data needed (minimum)

- products produced

- references.

The DSP library is searchable by these attributes. Thus, the user can search for all uses of a particular tool. For an expert user, the selection of analytical tools may be critical. Selection of a tool will then drive a reformulation of the DSP.

\section{Strategy for Implementation}

Implementation should follow these steps:

- Define a model for a DSP. This would include attributes and methods for combining DSPs and updating them as tools change.

- Develop a case study. Build a set of DSPs for a particular problem domain.

- Develop a search and presentation scheme for users.

- Integrate a lessons learned capability and a way for users to evaluate the DSPs.

- Develop a web site to improve user access.

- Address the issue of getting new DSPs. Perhaps there could be contractual language that would require contractors to input their process and results in an electronic form in addition to the normal printed documents. 


\section{In Summary}

Fundamentally, knowledge management makes the collective information and experience of an enterprise available to the individual knowledge worker, who is responsible for using it wisely and for replenishing the knowledge asset. This ongoing cycle promotes a learning organization, stimulates collaboration, and empowers people to continually enhance the way they perform work. 


\title{
6 Computation, Communication, and Data Storage
}

\author{
by Douglas M. Johnston
}

\section{Introduction}

\section{What Is Issue/Objective?}

The rapid development of ever higher performance computing and communications seems to continue unabated. Power that exceeds supercomputers of 10 to 15 years ago, which cost millions of dollars, are now available on the desktop for less than $\$ 2,000$. Network communications used by a small number of academic and government researchers is now accessible to virtually all people through browser and Internet technologies. While there is little doubt that increasing scalable networking and computation power is being developed, there is also a concern that there is a deficiency in comparable development in language, tools, and interface environment to make this power usable to a broader (i.e., nonscientific) community. Usable power refers to making access to the computational resources easier, by reducing or removing the considerable barriers that remain.

Numerous barriers to more effective use in the decisionmaking environment remain. The information environment remains disorganized; relevant data are distributed across many databases and systems that have differing descriptions, based on disciplinary focus. Models for analysis or creation of data are similarly distributed and disciplinary. Thus decisionmakers, confronted with a problem to solve, must seek out relevant data, acquire that data, transform it to a common framework, identify the models that will address the problem being solved, acquire the computational resources required to run the models, and finally, if all goes well, actually begin to address the real problem they set out to solve.

Consequently, the objective of technology applied to decisionmaking is to make resources (computational, data, model) available at the right time, to be applied to the right problem. The focus of this discussion is on methods for making resources available to the user. 


\section{Status}

In many respects, the technological advances in the last few decades, and in the last few years, have greatly enabled access to information resources. The rapid growth of distribution of information over the Internet and access through web browsers is certainly an indication of that. At the same time however, it has enforced the realization that physical access to information through networking is not the same as usable access. The proliferation of information on the World Wide Web has shown how unorganized and undocumented the information world truly is. Focusing only on geographic information resources, finding data for the location of interest, at the necessary scale, using an appropriate attribute domain, is itself a major challenge. The growth of clearinghouses and data catalogues is a step toward overcoming some of these barriers, and research efforts in digital library technologies promise advances as well.

In decisionmaking, data are only part of the equation. To assess the impact of events or predict the outcomes of alternative plans and policies, models are required to represent the processes or phenomena of interest. Models built by scientists can be extremely rich, but they can also be extremely opaque to a potential user who has the expertise to use the information generated by the models, but possibly not the disciplinary focus of the modeler. Arguably, many science models are built by scientists for scientists.

The world is also seeing a tremendous growth in the amount of data available. This is partly because more data are being stored in accessible (i.e., digital) forms, but also because more data are being collected. The launch of the new generation of remote sensing platforms promise wide coverage at very high resolution, but the price of that is the tremendous growth in the volume of data to be stored and analyzed. While the raw volume of storage capacities of magnetic drives and off-line storage continues, the issue of searching and rapidly accessing that information remains.

The development of common interface protocols developed through the PC "revolution" and more recently web browser technology for the Internet "revolution," has increased the provision of uniform access to resources by a larger audience (whose principle business is not the computational technology). Communications protocols such as TCP/IP have enabled higher levels of development built on top of these foundational technologies.

There is no question that there are good computers, good models, and good data available, but in many cases they are developed for single purposes by and for single disciplines. The fundamental issue in many cases is not a technical one, 
but an institutional one-of choosing to adopt standards, use protocols, provide access, etc. Nonetheless, technological advances in the infrastructure development can facilitate use of these formidable resources. The question is, how do we make models/data accessible to a broader user community?

\section{Needs/Requirements}

The problems of access to computational and information resources suggest that integration or logical connection between resources is a desired focus area. The following needs/requirements are proposed as areas of high priority:

- Data

- Cohesive data sets linked independently of individual projects.

- Data extraction and discovery tools

- Uniform means to access large data sets

- Data/Models/Interface

- Integrated Search capabilities

- Integration of storage media

* Primary (on line)

* Secondary (disk backup)

* Tertiary (tape storage)

- Models

- Model definition language

- Data input output specification

- Model documentation for suitability for use

- Interface

- Uniform/consistent understanding of available resources and access

- Push technologies (to notify of changes, etc.)

- Paradigms and tools to deal with large, hierarchical datasets, studies, knowledge.

\section{State of the Art Computation, Communication, and Data Storage}

\section{Large Storage}

There exist many approaches to management and storage of large datasets, including, on the hardware side, giga- and terabyte primary, secondary, and tertiary storage systems, and on the software side, several high-performance commercial systems such as Oracle, Informix, MSQL, etc. The principle issue in this arena is defining a mechanism for robust and efficient access to these systems. Network bandwidth available to the user, physical access to storage devices by 
users, overhead costs with maintaining large, complex datasets, data input output bottlenecks from storage to processor are a few of the issues that need to be addressed to keep up with the advances in online and archival storage. Of course, these issues are not unique to Federal Agency Decision Support. There are many efforts throughout the CS community to address these, e.g., the Hierarchical Data Format (HDF) (www.hdf.ncsa.uiuc.edu) developed for NASA,

\section{Simulation Models for Science}

Many models exist for various purposes. Even models for the same purpose employ different theoretical concepts of physical or social processes, different numerical algorithms for solving applications of the theoretical concepts, and certainly different programming languages, file types, data sources, etc. to execute the models. There is no question that there are good models and tools for a wide range of applications, and better ones (higher resolution, capturing finer and finer details of the phenomena, greater efficiency, etc.), but the issue remains from a users or market perspective of being to choose among them, or being able to assemble components to construct a system to address a particular class of problem that may span processes. At a foundational level, many technologies are being employed to facilitate the construction of complex, scientific models including the Modular Modeling System, DIAS, etc., to name a very few.

\section{Web Browsers}

It is easy to forget the birth of widespread use of the Internet, but the general public and all the e-commerce and other industries spawned from it started in the 1980 s with the world wide web consortium and in 1993 with the release of Mosaic, the first multi-function web browser. The development of web browsers, e-mail, on-line transactions, exchange of multi-media documents (and the tools to use them) and other technologies has enabled tremendous growth in the range of services available through the net (and the expectations associated with it). At the same time, the proliferation of search engines, agents, and other tools to find information show how difficult it currently is to find just the right piece of information. While highly structured information classification systems may limit the richness of information query, unstructured classification systems cannot guarantee access to information, even if it exists within the system.

The bottleneck to improved use of information and computation is argued here to be less an issue of needing greater advances in technological development (although technological development is critical), but more an issue of finding ways to increase the rate of adoption of existing and emerging technology by decisionmakers. Figure 7 illustrates the current state. 


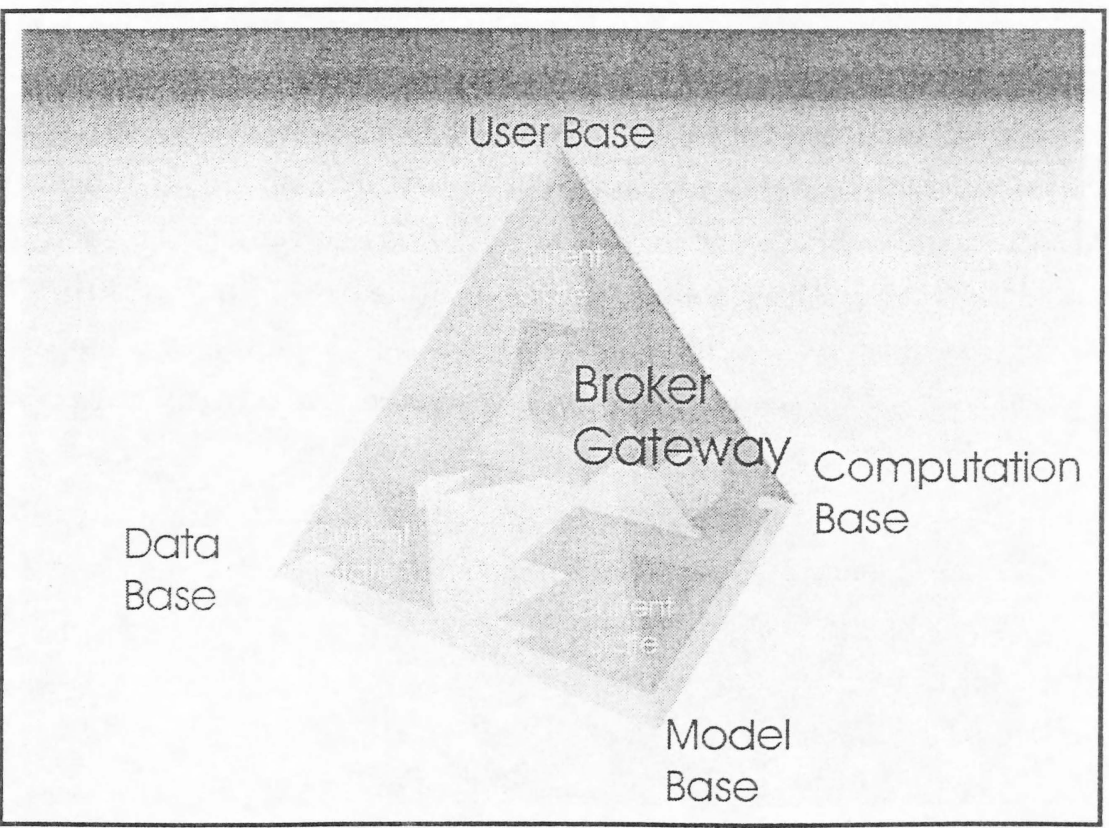

Figure 7. State of decisionmaking technology environment.

Components of the decisionmaking environment are shown as corners of the pyramid, as the data base, the model base, the computation base, and the user base. The volume of the pyramid represents the structure that links these components together. The solid gray corners represent the current state of development. In other words, we argue that the individual sectors (data base technologies, modeling tools, computational resources, and user interfaces) have each seen development, but filling the pyramid and the full integration of the resources remains incomplete.

\section{Vision for the Future}

There are two (not mutually exclusive) strategies for completing the structure. One strategy is to continue building from the corners, by developing faster computers, larger databases, better models, and better user interfaces. Another strategy is to create a new node in the center and build outward to join the foundational technologies where they currently exist, and co-develop along with these technologies. This node is termed a "broker," which represents a tiered set of services built to connect the technologies in ways that can bring existing capabilities to bear fruit quickly. 


\section{Broker}

The broker functionality is borrowed from the familiar services sector. A broker provides a means of filtering through available options and presenting a more limited set of comparable options for subsequent action. The architecture for this broker service (Figure 8) consists of a set of components providing the information needed to filter through the information. Noted that some of the barriers presented above exist here, but the emphasis here is on confronting those barriers directly by providing a tiered approach to implementation.

\section{Catalogs}

The foundational element of the broker function is to construct catalogues that provide information on the available elements (products). The catalog contains the attributes of the elements and a method to query these attributes.

\section{Abstraction}

The definition of attributes of catalog elements requires the creation of model, data, and computation abstractions, that is, generalizable descriptions of relevant features that form the structure of the query and can be populated by the producers of the elements. The abstraction is independent of specific implementations (programming languages, units of analysis, dates of record, etc.).

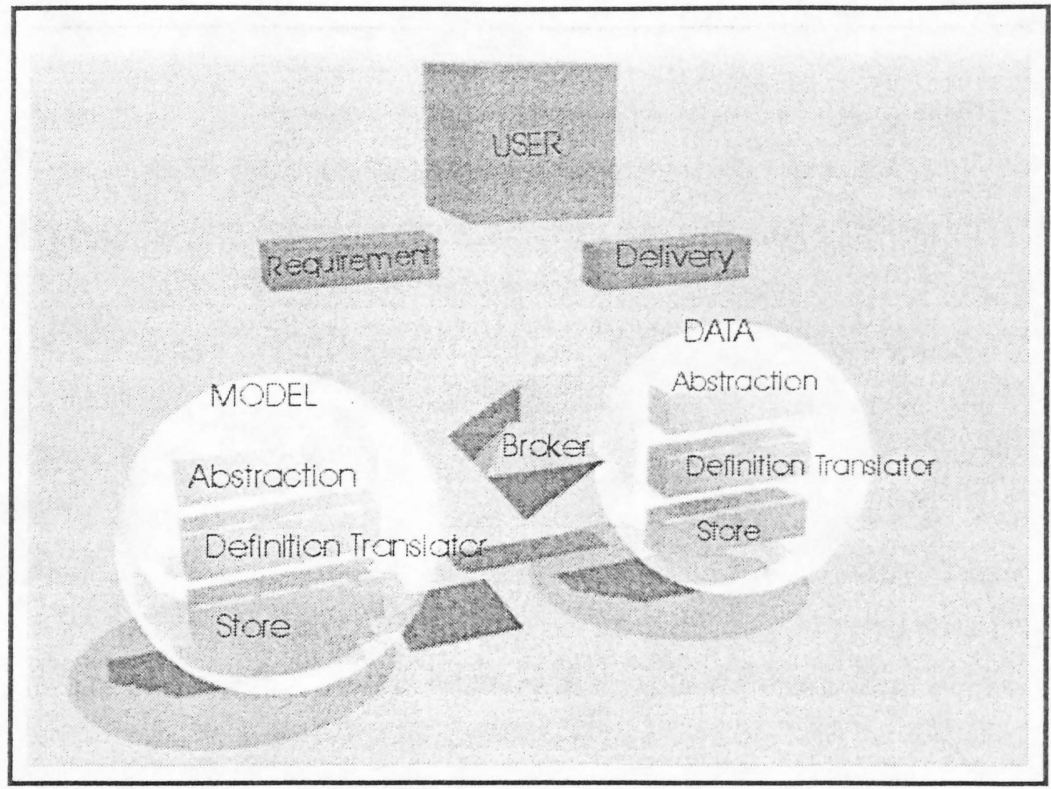

Figure 8. Broker services architecture. 


\section{Definition Translator}

It is assumed that it is not possible (or even desirable) to define or enforce a universal standard on model/data/computation specification or implementation. Thus, to map the abstract definition to the actual elements, a definition translator is required. In a shopper/catalogue/warehouse analogy, for example, the definition translator may take the product identification generated from the catalogue description, and return the resources required to ship it (size, weight, cost, special handling, etc.).

\section{Store}

The data or model store is characterized not as a monolithic data depository but rather a set of pointers to the actual resources. In a warehouse analogy, the store takes a particular product identifier and tells the warehouse operator where that product is located.

\section{Strategies for Implementation}

A multi-tiered strategy may well advance progress in this area is suggested. An overriding objective is to ensure that the decision support community is engaged in the process of defining and developing this functionality. The strategy is a market or user-focused approach to bridging the gaps between existing technologies:

- Tier 1

- Literature review on model definition language. Data definition languages through metadata specifications and interoperability activities are advancing rapidly. A similar effort for models needs to be launched.

- Test against Marketplace. Arguably, one of the barriers to decision support technology is the perceived lack of market potential by private sector technology providers.

- Government Influence on Technology Trajectory. The creation of broker services can be disabled by the unwillingness of stakeholders to participate, even if the functions perform to specification. As these efforts develop, the government can assist by including requirements in contracts and bids supporting participation.

- Enable Access to Data. To capture "low hanging fruit," demonstration functions supporting brokered access to distributed data should be supported. This need not necessarily require new programs; it can occur 
through existing demonstration projects undertaken by the Federal agencies.

- Tier 2

- De-Couple Models

- Formalize Definition Models

- Basic Broker Functionality (search/discovery)

- Maintain connection with CS community re GRID development.

- Tier 3

- Advanced Broker Function

- Implement within emerging computational GRID environment (second generation Web).

\section{Recommendations}

1. Workshop aimed at defining model components
a. Model Description Language
b. Based on fundamental cleavages between types
c. Look at ERDC Model catalog

2. Form multilateral evaluation group (e.g., OGC)

3. Make case for market

4. Need a synoptic program/ for teaching and research

5. Consortia/partnership of compute service providers/ISP/and ASP.

\section{Roles}

- Government Specifications and Requirements

- Consortia-Standards

- Industry - Widgets. 


\title{
7 Discussion
}

\author{
by Gene Lessard
}

\section{Placed-Based Decisionmaking}

Assuming that the answer to the Aurora Partnership question (posed in Chapter 1 ) is that, yes, an affiliation of academics, industry, and government can help to more rapidly and effectively shape and realize the potential advantages of these technologies, the next issue to resolve is to determine how to speed improvements in placed-based decisions through collaborative technology initiatives, and to determine the critical steps. The first step is to envision and communicate the most desirable way for technology to aid in our future decision processes. This requires a strong dialogue between the developers/pioneers of different technology innovations, and placed-based decisionmakers. The better desirable end states in decision processes are described, the better designers will be able to shape technologies to help us achieve these end states. Conferences, publications, talks, and web site demonstrations can all help elicit descriptions of these future decision capabilities and nurture a strong and interacting community of technology developers and pioneer users.

\section{Who Has What Role?}

There are roles for government organizations (at multiple tiers), educational institutions, industry, and nongovernment organizations aimed at shaping improved future placed-based decisionmaking. However, the roles for any one task are not necessarily distinct. For instance, research can be performed by government, academics, and private firms alike. In general, Table 2 outlines the roles for the various players. 
Table 2. Participants and roles that shape improved future place-based decisionmaking.

\begin{tabular}{|c|c|c|c|c|c|c|}
\hline Participant & Communicate a Vision & Demonstrations & $\begin{array}{l}\text { Repositories } \\
\text { and Templates }\end{array}$ & $\begin{array}{l}\text { Interoperative } \\
\text { Products }\end{array}$ & $\begin{array}{c}\text { Build Local } \\
\text { Capacity/Experts }\end{array}$ & $\begin{array}{l}\text { Building } \\
\text { Frameworks }\end{array}$ \\
\hline $\begin{array}{l}\text { Communities and } \\
\text { Regions }\end{array}$ & Help to shape vision & $\begin{array}{l}\text { Conduct demos } \\
\text { on local issues }\end{array}$ & $\begin{array}{l}\text { Draw from and } \\
\text { contribute to } \\
\text { repositories }\end{array}$ & $\begin{array}{l}\text { Use/ require } \\
\text { interoperable } \\
\text { products } \\
\end{array}$ & $\begin{array}{l}\text { Build sustaining } \\
\text { capability through } \\
\text { demos }\end{array}$ & $\begin{array}{l}\text { Focus market } \\
\text { demands towards } \\
\text { highest needs }\end{array}$ \\
\hline $\begin{array}{l}\text { Federal Agencies } \\
\text { and } \\
\text { Organizations }\end{array}$ & $\begin{array}{l}\text { Facilitate the shape of } \\
\text { the vision through } \\
\text { workshops and research } \\
\text { partnerships }\end{array}$ & $\begin{array}{l}\text { Resource and } \\
\text { participate in } \\
\text { demo programs }\end{array}$ & $\begin{array}{l}\text { Build repositories } \\
\text { for objects, } \\
\text { lessons learned, } \\
\text { processes }\end{array}$ & $\begin{array}{l}\text { Use/require } \\
\text { interoperable } \\
\text { products and } \\
\text { develop scopes of } \\
\text { work }\end{array}$ & $\begin{array}{l}\text { Encourage } \\
\text { capability building } \\
\text { through demo } \\
\text { programs }\end{array}$ & $\begin{array}{l}\text { Create overarching } \\
\text { information technology } \\
\text { concepts and } \\
\text { approaches for } \\
\text { "seamless" capabilities }\end{array}$ \\
\hline $\begin{array}{l}\text { Consortia and } \\
\text { Standards } \\
\text { Organizations }\end{array}$ & $\begin{array}{l}\text { Build standards } \\
\text { responsive to vision/ } \\
\text { approach }\end{array}$ & $\begin{array}{l}\text { Operate test- } \\
\text { beds }\end{array}$ & $\begin{array}{l}\text { Help nurture } \\
\text { standard } \\
\text { approaches for } \\
\text { repositories } \\
\end{array}$ & $\begin{array}{l}\text { Focus standards } \\
\text { efforts on inter- } \\
\text { operability }\end{array}$ & $\begin{array}{l}\text { Use test-beds to } \\
\text { help build/sustain } \\
\text { capacity }\end{array}$ & $\begin{array}{l}\text { Develop standards } \\
\text { that facilitate } \\
\text { frameworks }\end{array}$ \\
\hline Academics & $\begin{array}{l}\text { Conduct research and } \\
\text { education towards future } \\
\text { decision technologies } \\
\text { and processes }\end{array}$ & $\begin{array}{l}\text { Participate/assist } \\
\text { in demos }\end{array}$ & $\begin{array}{l}\text { Develop concepts } \\
\text { and prototypes }\end{array}$ & $\begin{array}{l}\text { Develop concepts } \\
\text { and participate in } \\
\text { test-beds }\end{array}$ & $\begin{array}{l}\text { Collaborate with } \\
\text { local/regional } \\
\text { entities to } \\
\text { build/sustain } \\
\text { capabilities } \\
\end{array}$ & $\begin{array}{l}\text { Develop concepts and } \\
\text { prototypes }\end{array}$ \\
\hline Private Firms & $\begin{array}{l}\text { Affirm vision with } \\
\text { responsive products and } \\
\text { services }\end{array}$ & $\begin{array}{l}\text { Provide resource } \\
\text { assistance }\end{array}$ & $\begin{array}{l}\text { Develop } \\
\text { capabilities that } \\
\text { utilize repositories }\end{array}$ & $\begin{array}{l}\text { Form consortia and } \\
\text { provide test-bed } \\
\text { involvement to } \\
\text { make interoperable } \\
\text { tools }\end{array}$ & $\begin{array}{l}\text { Focus grants and } \\
\text { assistance towards } \\
\text { capability building }\end{array}$ & $\begin{array}{l}\text { Build tools and } \\
\text { services that fit into, } \\
\text { expand and are } \\
\text { compatible across } \\
\text { frameworks }\end{array}$ \\
\hline
\end{tabular}




\title{
8 Summary and Recommendations
}

\author{
by Gene Lessard and William D. Goran
}

\section{Summary}

Decision support systems have been defined in many ways to reflect different emphases or points of view. This workshop defined Place-Based Decision Support Systems (PBDSS) as combinations of computer hardware, software, data, and models that allow users to better understand complex issues, develop alternative approaches to resolving those issues, and test them within a "what if" environment. Geographic information systems (GIS) are clearly a crucial element of such systems, but need to be augmented by additional decision support tools.

The combination of new capabilities and growing demand are generating greater expectations for decision support, and identifying new challenges for developers and users alike. This workshop was intended to discuss challenges and opportunities to meet these expectations and to outline the next steps in a strategy for the next stage of PBDSS development. In discussions, meetings and workshops over the last several years, the IGDS and the Aurora Partnership have identified several topical areas:

- decision processes

- collaborative tools for decision support

- information management and interóperability

- knowledge management and decision support

- computation, communication, and data storage.

Issues are explored within the context of a decisionmaking processes currently being used (Chapter 2). Decisionmaking is the result of a sequence of implicit or explicit steps. Decisionmaking can be seen as a generalized, stepped process, consisting of: process mapping, problem framing, intelligence gathering, evaluating and choosing alternatives, and learning from the outcome of the decision. This decision process is often a function of the type of decision to be made. For instance, decisions made under the National Environmental Policy Act have legal, well-documented procedures to follow. Other routine decisions may involve only a portion of the process. Lastly, collaboration is often an essential ingredient in decisionmaking. These three aspects-the process, the type of decision, 
and the need for collaboration-encompass the environment in which decision support systems and tools will be used.

In the future, decisionmakers may have:

a toolbox containing a variety of tools to help address the range of placebased problems. Some tools would assist in understanding and improving the process itself; others would assist specific stages, such as intelligence gathering or evaluating alternatives; still others would help identify very specific tools for specific problems or parts of problems (e.g., hydrologic models). New tools could be added as new problems arise or as conditions change, without the need to extensively modify or replace either the toolbox or existing tools. The interface would be consistent, and learning about the capabilities of the toolbox and the geographic area being considered would be cumulative. The toolbox would be one of many offered by different vendors, and all would be capable of incorporating tools from other sources.

Assuming that collaboration will be a major part of the decisionmaking environment, it seems reasonable to develop tools specifically to enhance the collaborative process. Chapter 3 notes that "collaborative tools can help in two important ways. First, they can serve as tools to apply proven group decision support methods and processes. Second, they can serve as an aid in helping group members arrive at a shared understanding of technical information relevant to their issues." In addition, collaborative tools can allow stakeholders to work at their own time (asynchronous) and place (distributed) versus the traditional "town meeting" venue (synchronous and collocated). The author notes that "effective collaborative tools should help stakeholders in a decision process to arrive at better decisions when measured against metrics of consensus, awareness, representation, time, and/or cost."

To arrive at a vision for the future of collaborative tools, some of the impediments to effective collaboration were examined. These include such factors as organizational competition, identification of stakeholders, the knowledge and skill of individual stakeholders, and others. With these impediments in mind, collaborative tools can accomplish three goals: to develop shared purpose, to develop shared understanding, and to provide a focus for resources.

Any decisionmaking process requires data that can be converted into information and, ultimately, into knowledge. This conversion process needs to be managed in a transparent manner to the user. Chapter 4 notes that "information management involves the purposeful, directed manipulation of data as it moves from in- 
formation (e.g., inputs for decisionmaking) to knowledge (e.g., belief and value sets used as overarching constraints, goals, and objectives in decisionmaking)." Also, "interoperability is defined as the capability of productively and seamlessly moving from data to information to knowledge, and back, in a manner whose infrastructure is transparent."

This vision for the future focuses on the "seamless movement of data, information, and management from research to analysis to synthesis to adaptation. This is particularly true ... where new science findings must flow to implementation, and where feedback produces the need for adaptation of a given management decision." With this in mind, five areas of functionality for interoperable information systems are:

1. Access. Differing stakeholders should be able to use different components of an interoperable information system from their geographically distributed desktops.

2. Catalog. The system should provide for a repository for techniques/algorithms in a standard, web-searchable paradigm.

3. Smart Agent/Knowledge Management. Methods should be developed to capture the knowledge base, sharing "lessons learned," decision model," "case studies," etc. for repositing in the cataloging framework above.

4. Motivation. Mechanisms should be put in place to strongly encourage the development of in-house and marketplace interoperable solutions.

5. Processing. Encourage interoperability and reuse of tools through standards.

Knowledge is an asset that needs to be managed. However, knowledge management presents many additional dilemmas. Chapter 5 identifies knowledge management as:

an integrated, systematic approach to identifying, managing, and sharing an enterprise's information assets, including documents, databases, policies, procedures, and implicit expertise. The purpose of this integration is to make available the validated "Decision Support Process" that will guide the user to the decision point.

Fundamentally, knowledge management makes the collective information and experience of an enterprise available to the individual knowledge worker, who is responsible for using it wisely and for replenishing the knowledge asset. This ongoing cycle promotes a learning organization, stimulates collaboration and empowers people to continually enhance the way they perform work. 
This vision of the future for knowledge management includes a "searchable distributed library of Decision Support Processes" (DSPs) in which each DSP is a "complete 'case study' of the process, data requirements, analytic tools ..."

The identification of a decision process, the need for and use of collaboration (Chapter 2), development of collaborative tools (Chapter 3), managing data, information (Chapter 4), and Knowledge (Chapter 5) all seem straightforward. In fact, it can be argued that organizations are already doing all of the above. However, as Chapter 6 notes:

the information environment remains disorganized with relevant data distributed across many databases and systems with differing descriptions based on disciplinary focus. Models for analysis or creation of data are similarly distributed and disciplinary. Thus decisionmakers, confronted with a problem to solve, must seek out relevant data, acquire that data, transform it to a common framework, identify the models that will address the problem being solved, acquire the computational resources required to run the models, and finally, if all goes well, actually begin to address the real problem they set out to solve.

Given this observation, the objective of applying technology to decisionmaking is to "make resources (computational, data, models) available at the right time to the right problem." The problem with technology application is more institutional in nature than technical. Organizations choose not to adopt standards, not to use protocols, or not to provide access to information. Chapter 6 presents the concept of a "broker" which represents a "tiered set of services built to connect the technologies in ways that can bring existing capabilities to bear fruit quickly." A broker filters through available options and presents a limited set of comparable options. The foundation of the broker concept is the "catalog," which contains available elements or products and a method for querying. An abstraction defines attributes, a definition translator matches abstract definitions to actual elements, and a store provides a set of pointers to the actual resources.

\section{Recommendations}

\section{Conduct Demonstration Programs}

The work groups that contributed to this study emphasized a number of themes. The first of these was the need for demonstration programs focused only in part on addressing a specific local issue. A clear additional goal of these demonstra- 
tion programs would be to leave a legacy of capability within the community that will be applied to future issues. Place-based issues are seldom "one time/one decision" in nature. Rather, these issues need to be continuously addressed and the public and stakeholders frequently informed.

One important goal of a program to develop and demonstrate improved placebased decisionmaking is to grow sustainable capabilities for localities and regions. To help encourage this capacity building, demonstration and test-bed programs should use one metric for success relating to the "sustainable capability creation." This capacity building has several dimensions, embodied in the following questions:

- Have stakeholders learned to work better together?

- Is there local available expertise in the technologies needed to support improved place-based decisions?

- Is there a process in place to obtain relevant data, especially dynamic data elements?

- Is there an improved climate in the community/region for decisionmaking?

Demonstrations can be conducted within existing Federal, State, or privately sponsored programs, or could be a context for fashioning new programs. Metrics for success would not just be related to the successful use of some new capability in a decision process, but to the successful transition of this capability into the local community, and the contribution of lessons learned about this capability back to a network of developers and other potential placed-based users. Metadata about applications and lessons learned would be contributed towards web accessible repositories to help inform increase the body of available expertise and experts.

Specific recommendations for demonstration programs from the workshop are:

1. Develop a set of case studies and/or other "lessons learned," including evaluations of tools and applications, meta-analyses and retrospectives on past place-based activities.

2. Initiate a series of linked demonstration projects, each of which will be designed to improve the support for the decision process.

3. Develop and conduct a series of highly-focused technologies that, by design, investigate the best of several means for achieving interoperable information technologies. Envisioned is a set of five to seven demonstrations, chosen to reflect differing natural and water resources decision processes, each with differing stakeholder requirements, that exercise the differing interoperability and information aspects listed above. It is recommended that the Federal government 
agencies with major roles in the natural and water resources area come together to establish these demonstrations in direct concert with stakeholder groups and industry.

4. Develop a case study. Build a set of DSPs for a particular problem domain.

5. Integrate a lessons learned capability and a way for users to evaluate the DSPS.

6. Focus on the establishment of a national center or centers that will coordinate a small number of test-bed programs while providing collaborative implementation toolkits to groups that are interested in experimenting with place-based decision support. An alliance of Federal and State agencies, standards organizations, vendors, and consultants should pool resources on a voluntary basis to:

a. Encourage local centers for Place-based Decision Support

b. Act as a repository and resource for "best practice" process templates

c. Act as a repository and resource for lessons learned

d. Provide free or low cost visualization, modeling, and scenario generation tools

e. Fund a small number of pilot demonstration programs.

\section{Repositories and Catalogue Services}

Creation of repositories and catalogue services is another important step in facilitating local decisionmaking. Such services are needed to ensure that relevant data, expertise, software, and process information all gets to the right persons at the right time in the right format. Creation of networks of services that are "registered" against local applications will help connect relevant experts, data and expertise with local community and regional efforts. Applications of decision technology both draw from and contribute towards these repositories and catalogue services-and the network of services grows in terms of both the availability of data and the processing of relevant information with each application conducted.

Specific recommendations for creation of repositories and catalogue services from the workshop are:

1. Develop open "wizards" that facilitate placing data within web-accessible repositories. Define these repositories using standards so that they can be queried and mined by different users who see them as virtual repositories.

2. Develop a consistent, integrated problem-solving computational environment (a "decisioning" world on the web). Major Federal government organizations and 
industry should collaborate to provide the critical mass needed to properly develop the environment.

3. Develop a standard set of agents that act behind the scenes over a network or the web to facilitate data/information creation, location, and retrieval, model/tool selection, visualization, etc.

4. Develop a search and presentation scheme for users.

5. Develop a web site to improve user access.

\section{Standards for Interoperability}

Another important step is to develop and implement standards for interoperability of capabilities so that new functions easily fit into an extensible framework, and all capabilities from any vendor or data store can be used together. The Open GIS Consortium is dedicated to this end state, and various other standards groups are focusing on components of this goal. Such efforts are part of the critical path for future decisionmaking, because of the need to share and access data and tools and expertise relevant to any local issue, and because of the need to share across localities and regions.

Specific recommendations for standards for interoperability from the workshop are:

1. Develop and use one set of national interoperability standards.

2. Provide financial incentives through contracts to promote the use of established standards.

3. Eliminate designed noninteroperability ("not invented here"). Promote the use of standards through Agency order at the national or agency level.

4. Make new technology implementations transparent to the user. This would be done primarily through the use of object-oriented, modular developments, and through the use of standards/agents as listed above.

\section{A Framework Approach}

Besides implementing standards, agencies need to develop a framework approach into which all of their data, models, and commercial capabilities are mapped. These frameworks are needed to get disparate technology pieces (technical systems, business systems, commercial software, data bases) into a selfimproving, scalable, evolving, web-based context. This "framework" needs to eliminate requirements for duplicating data entry across systems. It should also automatically gathers data on users, applications, processes and usage context, 
create templates and process flows to reduce steps and avoid costs for future efforts, and draw on agency-wide stores of data and tools to seek experts and experience relevant to any specific task. Agency frameworks can drive the "interoperability" context for industry products, and can be mimicked at regional and local levels.

Specific recommendations for developing a framework approach from the workshop are:

1. Develop and inventory tools that can help assess decision processes (rather than decisions).

2. Develop a set of guides (probably through a World Wide Web site) to the process and the currently available tools and systems. Identify specific tools for different stages of the decision process.

3. Establish a new set of smart agents or wizards to monitor and feedback the actual processes used in decisionmaking for a given situation.

4. Provide a higher conceptual or natural language query capability to facilitate decision support to many stakeholders. Develop the means for decisionmakers to query data of all types (including modeling and simulation data) using terms (language) they understand and identify with.

5. Define a model for a Decision Support Process (DSP). This would include attributes and methods for combining DSPs and updating them as tools change.

6. Address the issue of getting new DSPs. Perhaps there could be contractual language that would require contractors to input their process and results in an electronic form in addition to the normal printed documents.

7. Inventory computerized tools that are currently available and which, with some modification, can aid in decisionmaking.

8. Initiate a "Request for Information" for PBDSS tools and systems, and begin a multi-agency evaluation and analysis of these tools and systems. 


\section{CERL Distribution}

Chief of Engineers

ATTN: CEHEC-IM-LH (2)

ATTN: HECSA Mailroom (2)

ATTN: CECC-R

Engineer Research and Development Center (Libraries)

ATTN: ERDC, Vicksburg, MS

ATTN: Cold Regions Research, Hanover, NH

ATTN: Topographic Engineering Center, Alexandria, VA

Defense Tech Info Center 22304

ATTN: DTIC-O

9

$6 / 00$ 


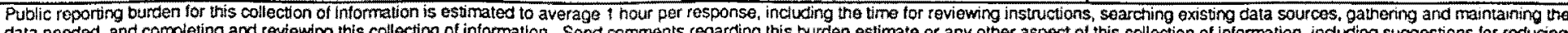

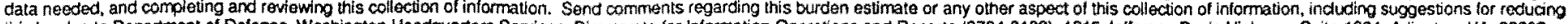

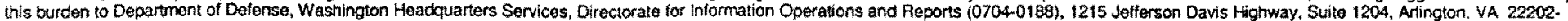

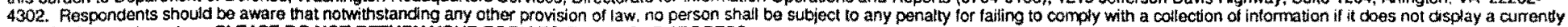
valid OMB controt number. PLEASE DO NOT RETURN YOUR FORM TO THE ABOVE ADDRESS

\begin{tabular}{l|l} 
1. REPORT DATE (DD-MM-YYYY) & 2. REPORT TYPE
\end{tabular} $01-2000$

Final

4. TITLE AND SUBTITLE

Decision Support Capabilities for Future Technology Requirements

3. DATES COVERED (From - TO)

5a. CONTRACT NUMBER

5b. GAANT NUMBER

5c. PROGRAM ELEMENT NUMBEA

6. AUTHOR(S)

Michael P. Case, William D. Goran, Thomas M. Gunther, Jeffery P. Holland, Douglas

Johnston, Gene Lessard, and Wayne J. Schmidt

5d. PROJECT NUMBER

622720 A917

5e. TASK NUMBER

5f. WORK UNIT NUMBER

8. PERFORMING ORGANIZATION REPOAT NUMBER

7. PERFORMING ORGANIZATION NAME(S) AND ADDRESS(ES)
U.S. Army Engineer Research and Development Center (ERDC)

Construction Engineering Research Laboratory (CERL)

ERDC TR-01-2

P.O. Box 9005

Champaign, IL 61826-9005

9. SPONSORING / MONITORING AGENCY NAME(S) AND ADDRESS(ES)

Headquarters, U.S. Army Corps of Engineers (HQUSACE)

441 G St., NW.

Washington, DC 20314-1000
10. SPONSORMONITOR'S ACRONYM(S)

CERD-ZC

11. SPONSOR/MONITOA'S AEPORT NUMBER(S)

\section{DISTRIBUTION/AVALABILITY STATEMENT}

Approved for public release; distribution is unlimited.

\section{SUPPLEMENTARY NOTES}

Copies are available from the National Technical Information Service, 5285 Port Royal Road, Springfield, VA 22161.

\section{ABSTRACT}

Managing land ("place-based") resources bas become a challenging task. Federal land resource managers face complex decisions to balance many goals. As decisionmaking becomes more complex, demands increase for technologies to help decisionmakers explore and evaluate issues, and channel participants towards endpoints and decisions. Since 1997, the Interagency Group on Decision Support (IGDS) has provided a forum for agency staff and stakeholders to meet and exchange information on currently available decisionsupport tools. The IGDS vision led to the establishment of the Aurora Partnership, which is a collaboration of government, university, and private sector organizations. The Partnership engages in an open collaborative process to share ideas, information, and technologies to advance tools and systems that will enable the practical use of natural and social science in decisionmaking. This work reflects the outcome of one of a series of workshops aimed at addressing the goals and objectives of the IGDS and the Aurora Partnership to: (1) improve the interoperability, modularity, and transferability of decision-support tools and services, (2) develop and apply decision science principles to place-based management decisionmaking, and (3) incorporate both the decision science principles and tools into a science-based decision support framework.

\section{SUBJECT TERMS}

management information systems decision support systems

16. SECURITY CLASSIFICATION OF:

a. REPORT

Unclassified

\section{b. ABSTRACT} Unclassified information management

knowledge management

\begin{tabular}{c|c|c|c|} 
& $\begin{array}{c}\text { 17. LIMITATION } \\
\text { OF ABSTRACT }\end{array}$ & $\begin{array}{r}\text { 18. NUMBER } \\
\text { OF PAGES }\end{array}$ & $\begin{array}{c}\text { 19a. NAME OF RESPONSIBLE PERSON } \\
\text { William D. Goran }\end{array}$ \\
$\begin{array}{c}\text { C. THIS PAGE } \\
\text { Unclassified }\end{array}$ & SAR & 52 & $\begin{array}{c}\text { 19b. TELEPHONE NUMBER (In- } \\
\text { clude area code) } \\
(217) 373-7202\end{array}$
\end{tabular}


DEPARTMENT OF THE ARMY

ENGINEER RESEARCH AND DEVELOPMENT CENTER

CONSTRUCTION ENGINEERING RESEARCH LABORATORY

$$
\text { PO BOX } 9005
$$

CHAMPAIGN IL 61826-9005

PRESORTED

STANDARD

U.S. POSTAGE PAID

CHAMPAIGN IL

PERMIT NO. 871

OFFICIAL BUSINESS 